\title{
Towards a Molecular Level Understanding of the Multi-Electron Catalysis of Water Oxidation on Metal Oxide Surfaces
}

\author{
Miao Zhang $\cdot$ Heinz Frei
}

Received: 17 October 2014/Accepted: 13 November 2014/Published online: 23 November 2014

(c) Springer Science+Business Media New York 2014

\begin{abstract}
Earth abundant metal oxides play a central role as catalysts in the essential chemical transformations of sunlight to fuel conversion, which are the oxidation of water and the reduction of carbon dioxide. The rapidly growing interest in renewable fuel generation by using the energy of the sun has recently led to substantial breakthroughs in the use of first row transition metal oxides as catalysts for oxygen evolution from water. Substantive improvements of rates and lowering of overpotentials have been achieved by exploiting materials properties on the nanoscale, or taking advantage of the synergy of multiple metals. Moreover, knowledge derived from mechanistic investigations with structure specific spectroscopy is accelerating efficiency improvements. Monitoring by timeresolved FT-infrared spectroscopy reveals the molecular nature of active sites, while in situ X-ray and optical spectroscopy under reaction conditions provides insights into the electronic structure of the surface metal centers participating in the catalysis. By combining the bond specificity of vibrational spectroscopy with the metal electronic structure specificity of optical, X-ray absorption or photoelectron spectroscopy, a complete understanding of active surface sites on metal oxides begins to emerge. Charge flow driving the chemical transformations probed by optical spectroscopy across time scales from ultrafast to very slow reveals the processes that control the productive use of charges delivered to the catalyst. Coupling of the water oxidation catalysis at a metal oxide catalyst with carbon
\end{abstract}

M. Zhang · H. Frei $(\bowtie)$

Lawrence Berkeley National Laboratory, Physical Biosciences Division, University of California, Berkeley, CA 94720, USA

e-mail: HMFrei@lbl.gov dioxide reduction at a heterobinuclear chromophore, which is the goal of the artificial photosystem approach, is demonstrated by a well-defined all-inorganic polynuclear unit.

Keywords Heterogeneous catalysis - Photocatalysis . Water oxidation - Spectroscopy $\cdot$ Surface reaction kinetics . Oxide supports

\section{Introduction}

Metal oxides play a central role in two essential catalytic transformations for the generation of renewable fuels from abundant resources, which are the reduction of carbon dioxide and the oxidation of water. When coupled together, these two reactions constitute a sustainable cycle, since use of the resulting fuel in a fuel cell or by direct combustion regenerates the reactants $\mathrm{CO}_{2}$ and $\mathrm{H}_{2} \mathrm{O}$. If powered by the sun, either in a single integrated system (artificial photosynthesis) or in a two-step configuration consisting of photon to electricity conversion by photovoltaics coupled to an electrolyzer, the cycle offers a path towards replacing fossil resources by renewable fuels. Realization of such a technology on a scale that will have an impact on global fuel consumption (terawatt scale) requires catalysts that are both robust and Earth abundant, properties shared by a variety of metal oxides. In the past several years, substantial breakthroughs have been made in engaging abundant metal oxides as efficient catalysts for water oxidation. Promising developments in metal/metal oxide based catalysis of carbon dioxide reduction are emerging as well. Nevertheless, catalysts for converting carbon dioxide to a fuel, especially a liquid transportation fuel with adequate activity operating at acceptable overpotential are a formidable challenge that has yet to be met. 
In the area of catalysts for water oxidation, recent efficiency improvements have been particularly impressive for first-row transition metal oxides. Taking early studies of electro- or photon-driven Co and Mn oxide catalysts as point of departure [1-16], development of nanostructured forms of these oxides featuring very high surface areas have dramatically increased turnover frequencies of $\mathrm{O}_{2}$ product formation per projected catalyst area [17-19]. The need for high turnover frequency per projected area in artificial photosynthesis is based on the requirement that the catalyst should keep up with the incident solar flux in order to minimize wasting of photons. Furthermore, controlled substitution of Co or Mn by a second metal such as $\mathrm{Ca}$ or $\mathrm{Li}$, partly inspired by the $\mathrm{Mn}_{4} \mathrm{O}_{4} \mathrm{Ca}$ catalyst complex of the natural photosystem (PS II) [20], was found to result in marked rate enhancements compared to monometallic oxides [21-24].

Understanding of reaction mechanisms at the liquidsolid or gas-solid catalyst interface is the key for guiding catalyst design and choice of reaction conditions for boosting efficiency. High efficiency in the context of solar light driven catalysis means conversion of a maximum fraction of the photon energy to chemical energy of the fuel, which requires that the catalyst operates close to the thermodynamic potential of water oxidation. Equally important, the majority of incident photons need to be utilized productively for the chemical transformation of water and carbon dioxide, especially at maximum solar intensity. Particularly helpful is the direct observation of surface chemical functionalities by structure specific spectroscopies under reaction conditions. If conducted with sufficient temporal resolution for capturing short lived intermediates and monitoring their kinetic behavior, knowledge can be gained about the kinetic relevancy and the role of a given surface species in the catalytic cycle.

In this article, we will focus on recent advances in the understanding of elementary catalytic steps of water oxidation on metal oxides based on monitoring by timeresolved FT-IR, steady state Raman, X-ray absorption and emission, X-ray photoelectron and transient optical spectroscopy under reaction conditions. From such studies, molecular level knowledge of surface intermediates is emerging that allows comparison with analogous transformations of homogeneous transition metal catalysts, deepening our mechanistic insights. Knowledge of the geometrical and electronic structure of the metal oxide catalyst material and its surface is very important for the understanding of structural motifs available for catalytic transformations to take place, and of pathways for the transport of charges from the location of injection to the catalytic sites. The new level of detailed understanding of catalytic mechanisms established by recent studies provides concrete guidance for improved designs of metal oxide catalysts. While primarily focusing on water oxidation, the article includes a discussion of a well-defined polynuclear oxide unit that accomplishes the direct coupling of the water oxidation chemistry with carbon dioxide reduction, thereby closing the photosynthetic cycle.

\section{Cobalt Oxide Water Oxidation Catalysts}

In the past several years, exploration of cobalt oxides as water oxidation catalysts has resulted in very substantial advances in terms of efficiency of this oxide material and the understanding of surface chemical functionalities responsible for the activity.

\subsection{High Turnover Frequency Through Nanostructuring}

Exploring the possibility of a several orders of magnitude increase of the number of Co surface centers of a $\mathrm{Co}_{3} \mathrm{O}_{4}$ particle through nanostructuring while at the same time providing a robust scaffold for a stable dispersion of the clusters, we developed crystalline $\mathrm{Co}_{3} \mathrm{O}_{4}$ nanorod bundles in mesoporous silica SBA-15. This mesoporous silica material consists of uni-dimensional channels of $8 \mathrm{~nm}$ diameter separated by walls of $2 \mathrm{~nm}$ thickness with interconnecting micropores. The synthesis consisted of wet impregnation of Co nitrate precursor followed by calcination at $550 \mathrm{C}[17,18]$, resulting in the formation of spheroid-shaped Co oxide nanoclusters shown in the TEM image of Fig. 1a (4 wt \% Co loading). Removal of the silica scaffold by etching reveals a nanorod bundle structure of the Co oxide cluster with the rods interconnected by small bridges, confirming that the catalyst is a replica of the SBA-15 pore structure (Fig. 1c, d). The atomic structure of the Co oxide clusters is crystalline $\mathrm{Co}_{3} \mathrm{O}_{4}$ (spinel) for both the 4 and $8 \mathrm{wt} \%$ sample, as shown by the XRD pattern [17] and most clearly evidenced by extended X-ray fine structure (EXAFS) data presented in Fig. 1b.

These high surface area clusters exhibit turnover frequencies (TOF) per projected area for $\mathrm{O}_{2}$ evolution from water under mild conditions ( $\mathrm{pH}$ 6) at room temperature that exceed by far those of unstructured $\mathrm{Co}_{3} \mathrm{O}_{4}$, micrometer sized crystals. The activity of the $\mathrm{Co}_{3} \mathrm{O}_{4}$ clusters in aqueous suspension was measured by driving the catalyst with a visible light sensitizer using the established light absorber $\left[\mathrm{Ru}(\mathrm{bpy})_{3}\right]^{2+}$ (bpy $=2,2^{\prime}$-bipyridine) in conjunction with $\mathrm{S}_{2} \mathrm{O}_{8}{ }^{2-}$ as electron acceptor $[16,25]$. The method involves excitation of the Ru complex by visible light $(476 \mathrm{~nm})$, resulting in instant oxidation to $\left[\mathrm{Ru}(\mathrm{bpy})_{3}\right]^{3+}$, a moderate oxidant $\left(\varepsilon^{0}=1.24 \mathrm{~V}\right.$ NHE$)$ upon electron transfer to persulfate. When encountering a $\mathrm{Co}_{3} \mathrm{O}_{4}$ cluster inside the SBA-15 channels, holes are sequentially transferred to 
Fig. $1 \mathrm{Co}_{3} \mathrm{O}_{4}$ nanocluster catalyst supported on mesoporous silica SBA-15. a TEM image of SBA-15 loaded with $\mathrm{Co}_{3} \mathrm{O}_{4}$ nanorod bundle (4 wt \%). b Co EXAFS data of reference). The lower FTEXAFS peak intensity for higher shells of the $4 \%$ sample is due to the small size of the particles. c Bare $\mathrm{Co}_{3} \mathrm{O}_{4}$ nanocluster after removal of the SBA-15 silica material using aqueous $\mathrm{NaOH}$ as etching agent. d Cartoon of catalyst structure. From Ref. 17, with permission

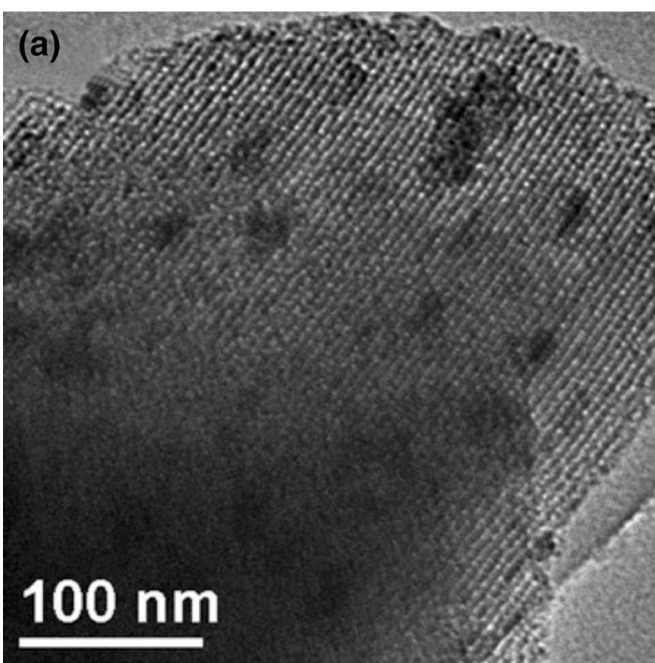

(b)

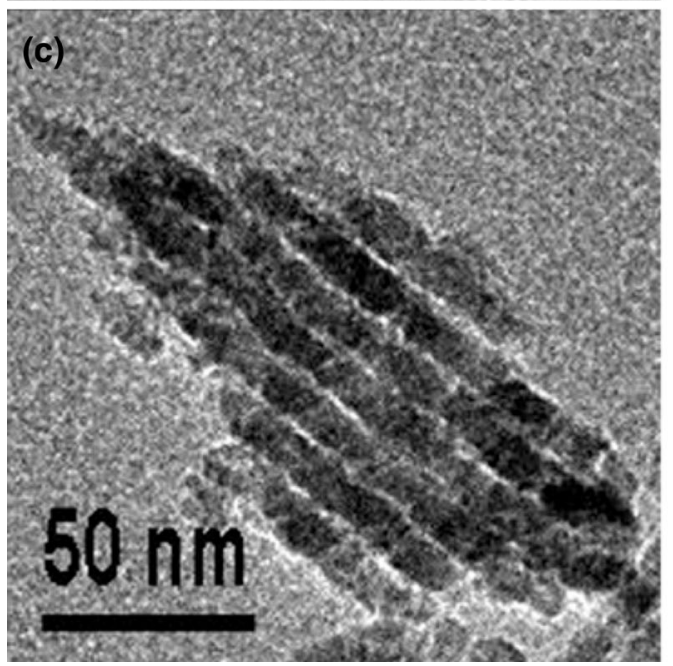

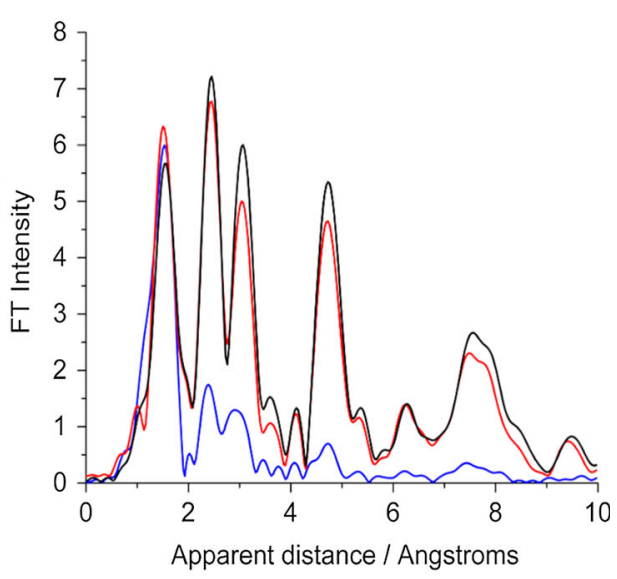

(d)

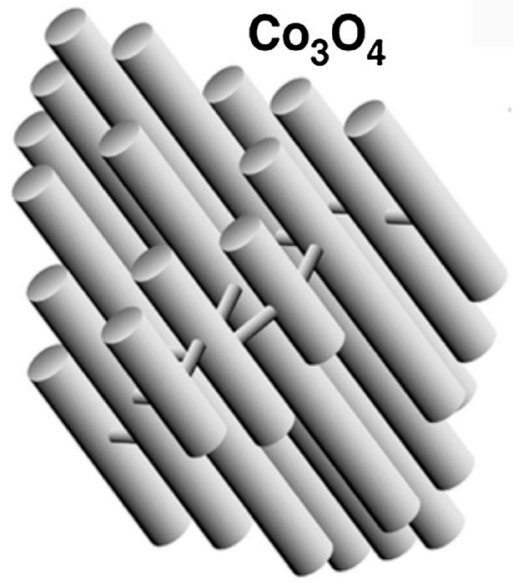

$\mathrm{Co}_{3} \mathrm{O}_{4}$ [17]. This sensitizer system is a convenient surrogate for catalyst activity evaluation and mechanistic studies, and is replaced by all-inorganic heterobinuclear light absorbers in artificial photosystems as described in Sect. 6. By measuring mass spectrometrically the $\mathrm{O}_{2}$ gas buildup in the head space of an aqueous suspension of SBA-15 particles loaded with $\mathrm{Co}_{3} \mathrm{O}_{4}$ nanoclusters (abbrev. SBA-15/ $\mathrm{Co}_{3} \mathrm{O}_{4}$ ) upon visible light sensitization, the $\mathrm{O}_{2}$ growth shown in Fig. 2 was obtained. From the linear rise of $\mathrm{O}_{2}$ over the initial $30 \mathrm{~min}$ of photolysis for the SBA- $15 / \mathrm{Co}_{3} \mathrm{O}_{4}$ (4\%) catalyst (Fig. 2, trace d) and the total number of clusters suspended in the solution, a TOF of $1,140 \mathrm{O}_{2}$ molecules $\mathrm{s}^{-1}$ per $\mathrm{Co}_{3} \mathrm{O}_{4}$ nanocluster was calculated (the levelling off of the $\mathrm{O}_{2}$ buildup around $60 \mathrm{~min}$ of photolysis is due to depletion of persulfate acceptor. Replenishing the solution with acceptor resulted in continued water oxidation at the original rate, indicating undiminished activity of the catalyst) $[17,18]$. The projection of the $35 \mathrm{~nm}$ diameter

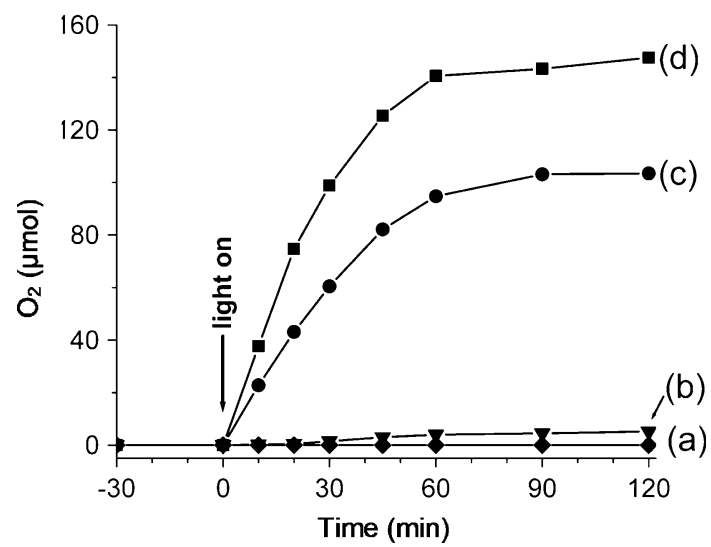

Fig. 2 Oxygen evolution in aqueous suspensions recorded by mass spectroscopy of a SBA- $15 / \mathrm{NiO}(8 \%)$ serving as catalytically inactive control. b Micrometer sized $\mathrm{Co}_{3} \mathrm{O}_{4}$ particles. c SBA- $15 / \mathrm{Co}_{3} \mathrm{O}_{4}(8 \%)$. d SBA- $15 / \mathrm{Co}_{3} \mathrm{O}_{4}(4 \%)$. Measurements were conducted at $\mathrm{pH} 5.8$ and $22{ }^{\circ} \mathrm{C}$. From Ref. 17, with permission 
spheroidal cluster on a plane perpendicular to the solar beam is $1,000 \mathrm{~nm}^{2}$, which gives a TOF per projected area of the catalyst around one $\mathrm{O}_{2}$ molecule $\mathrm{s}^{-1} \mathrm{~nm}^{-2}$. A rate of $100 \mathrm{O}_{2} \mathrm{~s}^{-1} \mathrm{~nm}^{-2}$ is sufficient for keeping up with the photon flux at maximum solar intensity (at noon in summer) [18]. Therefore, stacking of an average of $100 \mathrm{Co}_{3} \mathrm{O}_{4}$ clusters, which can readily be achieved by pressing a powder of SBA- $15 / \mathrm{Co}_{3} \mathrm{O}_{4}$ particles into a thin wafer $(150 \mu \mathrm{m}$ thickness for $4 \%$ loading) provides a catalyst sample for water oxidation that is both kinetically and thermodynamically competent (the overpotential is a moderate $350 \mathrm{mV} \quad\left(1.24-0.89 \mathrm{~V}, \varepsilon^{0}\left(\mathrm{O}_{2} / \mathrm{H}_{2} \mathrm{O}\right)=0.89 \mathrm{~V}\right.$ NHE at $\mathrm{pH}$ 5.8).

Comparison of the water oxidation activity of the SBA15 supported $\mathrm{Co}_{3} \mathrm{O}_{4}$ nanostructured clusters with the activity of micron size $\mathrm{Co}_{3} \mathrm{O}_{4}$ particles (Fig. 2, trace b), normalized to equal weight, reveals a 1,550 times higher $\mathrm{O}_{2}$ evolution rate for the $35 \mathrm{~nm}$ nanorod bundle catalyst. The principal factor for the several orders of magnitude higher rate of the nanostructured $\mathrm{Co}_{3} \mathrm{O}_{4}$ is the nearly 100 times greater number of surface $\mathrm{Co}$ centers per geometrical oxide surface area. We attribute the additional factor of 16 larger TOF value for the nanorod bundle catalyst to the correspondingly higher activity of its surface Co centers compared to those of the $\mu \mathrm{m}$ sized particle. The enhanced activity could be due to a higher density of surface motifs with adjacent $\mathrm{Co}{ }^{\mathrm{III}} \mathrm{OH}$ groups $\left(\mathrm{Co}{ }^{\mathrm{III}}(\mathrm{OH})-\mathrm{O}-\mathrm{Co}^{\mathrm{III}} \mathrm{OH}\right)$ in the case of nanorod bundles in silica, which were recently identified as highly active catalytic sites (Sect. 2.2). Assuming that all surface Co centers of the crystalline $\mathrm{Co}_{3} \mathrm{O}_{4}$ nanorod bundle are catalytically active, we calculate an average TOF per surface Co center of of $0.01 \mathrm{O}_{2} \mathrm{~s}^{-1}$ [17]. These findings have recently been confirmed and expanded by work from other laboratories. For example, a comparison of the water oxidation activity of surfactantfree $3 \mathrm{~nm} \mathrm{Co} \mathrm{C}_{3} \mathrm{O}_{4}$ particles in aqueous pH 6 solution with the same nanoparticles supported on SBA-15 using the same visible light sensitization method, Grzelczak et al. confirmed the significantly improved yields for the SBA- 15 supported particles because of the prevention of particle aggregation [26]. Jiao and his colleague reported the higher activity $\mathrm{Co}_{3} \mathrm{O}_{4}$ nanoparticles inside SBA-15 as well. Interestingly, the same $\mathrm{Co}_{3} \mathrm{O}_{4}$ nanoparticle catalysts in mesoporous silica KIT-6 with its 3-dimensional network of $8 \mathrm{~nm}$ channels perform even better than in SBA-15, presumably because of more facile diffusion of sensitizer and reactants in this more accessible channel system [27].

TOF values were subsequently reported for electrocatalytically driven cubical $\mathrm{Co}_{3} \mathrm{O}_{4}$ nanoparticles (range 5-50 nm) under basic ( $\mathrm{pH} \mathrm{14)} \mathrm{conditions.} \mathrm{For} \mathrm{these} \mathrm{mea-}$ surements, the Co oxide crystals were supported by a $\mathrm{Ni}$ foam anode [28]. According the electrochemical measurements the TOF per nanoparticle increases linearly with the accessible surface area of the particle. This finding supports the conclusion that the catalytic activity is proportional to the number of exposed Co centers. The tenfold higher TOF $=0.12 \mathrm{O}_{2} \mathrm{~s}^{-1}$ per surface Co center at $\mathrm{pH} 14$ [28] compared to 0.01 at $\mathrm{pH} 6$ is in agreement with the more facile oxidation of hydroxide ion compared to $\mathrm{H}_{2} \mathrm{O}$ under neutral or acidic conditions. The catalytic yield dependence on the surface area of $\mathrm{Co}_{3} \mathrm{O}_{4}$ nanoparticles in this same size range was recently confirmed under visible light sensitized and close to neutral $\mathrm{pH}$ conditions [26]. In our most recent studies of surfactant-free $\mathrm{Co}_{3} \mathrm{O}_{4}$ nanocrystals $\left(5 \mathrm{~nm}\right.$ diameter) or $\mathrm{Co}_{3} \mathrm{O}_{4}$ nanotubes in aqueous suspensions at $\mathrm{pH} 7-8$, measurement of water oxidation activity with the $\mathrm{Ru}(\mathrm{bpy})_{3}$ visible light sensitizer approach revealed TOF values per surface Co center between 0.01 and $0.02 \mathrm{O}_{2} \mathrm{~s}^{-1}$ [29-31]. Hence, nanostructured crystalline $\mathrm{Co}_{3} \mathrm{O}_{4}$ proves to be a suitable catalytic material for water oxidation in a variety of morphological forms, which provides flexibility in developing various architectures for integrating the water oxidation catalyst into complete synthetic solar fuel conversion systems.

\subsection{Molecular Nature of Active Surface Sites Revealed by Transient FT-IR Spectroscopy}

While the observed activity of surface Co centers is in the proper range for designing catalyst morphologies that are able to keep up with the solar flux, further improvement of the rate to broaden the range of particle sizes and morphologies requires detailed knowledge of the active sites. Specifically, do most surface Co sites operate at TOF of $0.01-0.02 \mathrm{~s}^{-1}$, or are there sites running at much higher TOF while other surface Co centers barely contribute or even play the role of spectators? If so, what is the nature of the most active site? Knowledge of the structural motif of the most active site(s) and understanding of the elementary reaction steps is the key for guiding modifications of $\mathrm{Co}$ oxide surfaces for maximizing the TOF.

To answer these questions, we have conducted a mechanistic study of water oxidation on $\mathrm{Co}_{3} \mathrm{O}_{4}$ surfaces by time-resolved rapid-scan FT-IR spectroscopy using crystalline nanoparticles in aqueous solution [32]. A TEM image of the catalyst particles at $1 \mathrm{~A}$ resolution is shown in Fig. 3a [33]. The visible light sensitization method using the $\left[\mathrm{Ru}(\mathrm{bpy})_{3}\right]^{2+}$-persulfate system provided a straightforward means of pulsed charge (hole) delivery to the $\mathrm{Co}_{3} \mathrm{O}_{4}$ catalyst particles, which is required for obtaining temporally resolved spectra. An aqueous suspension of the surfactant-free $\mathrm{Co}_{3} \mathrm{O}_{4}$ nanoparticles held at $\mathrm{pH} 8$ was placed on an attenuated total reflection (ATR) element (3 reflection diamond plate, Fig. 3b). Upon illumination of the solution with a visible laser pulse $(476 \mathrm{~nm})$ of $300 \mathrm{~ms}$ duration to excite the sensitizer, two infrared bands were 


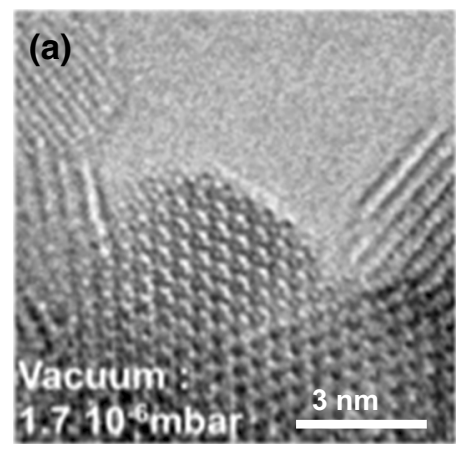

(b)

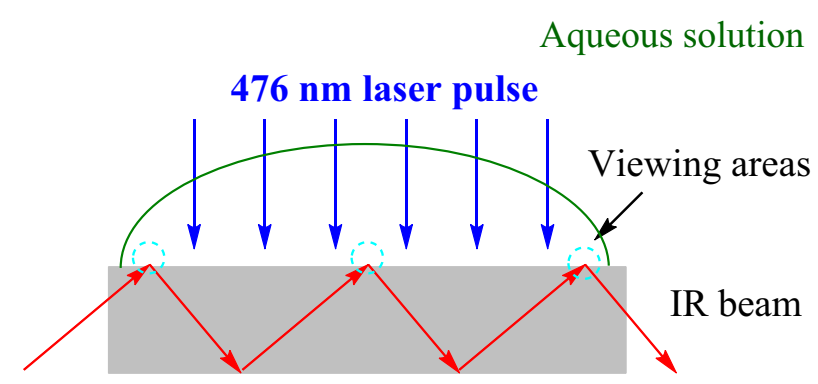

Fig. 3 a Atomic resolution TEM image of $5 \mathrm{~nm} \mathrm{Co}_{3} \mathrm{O}_{4}$ crystallite. b Sample configuration for rapid-scan ATR FT-IR spectroscopy. A visible laser pulse $(476 \mathrm{~nm}, 300 \mathrm{~ms})$ excites the $\mathrm{Ru}(\mathrm{bpy})_{3}$ sensitizer

detected that exhibit very different kinetic behavior. One species absorbs at $1,013 \mathrm{~cm}^{-1}$ (Fig. 4Aa) and shows ${ }^{18} \mathrm{O}$ isotopic counterparts in pure $\mathrm{H}_{2}^{18} \mathrm{O}$ at 995 and $966 \mathrm{~cm}^{-1}$ (Fig. 4Ab). The large, $47 \mathrm{~cm}^{-1}$ isotope shift of the $966 \mathrm{~cm}^{-1}$ band reveals an OO bond mode, while the $1,013 \mathrm{~cm}^{-1}$ frequency indicates a superoxide structure that
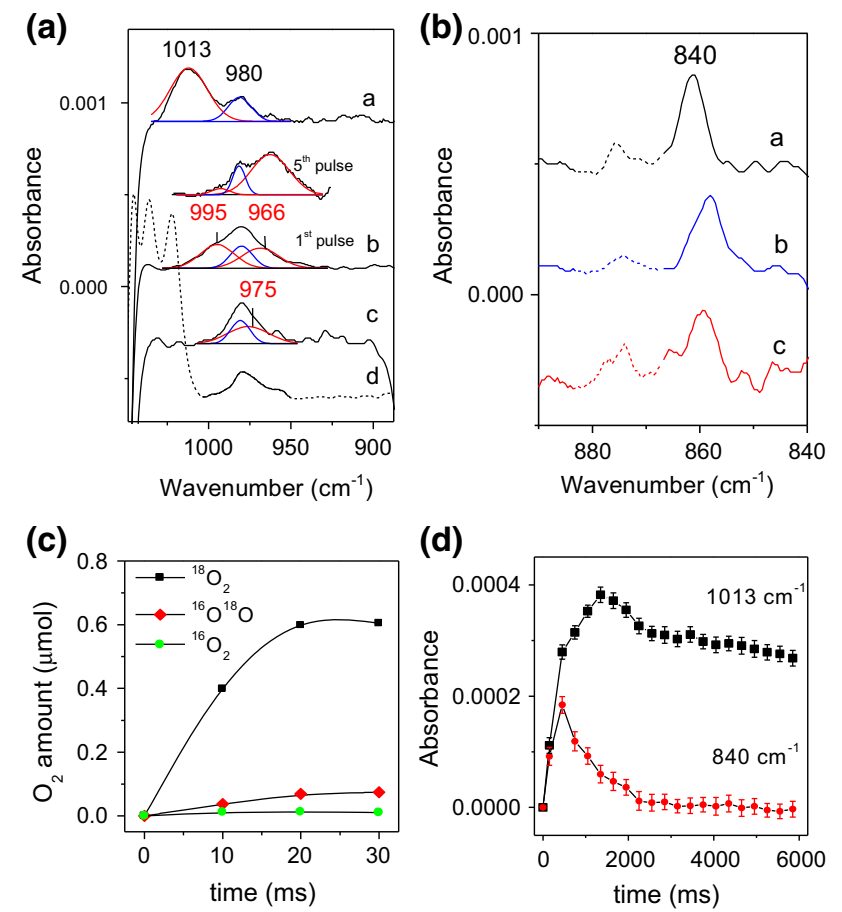

Fig. 4 Time resolved FT-IR monitoring of water oxidation catalysis at $\mathrm{Co}_{3} \mathrm{O}_{4}$ nanoparticles. a FT-IR of superoxide intermediate $\mathrm{Co}^{\mathrm{III}}$ (OO) $-\mathrm{Co}^{\mathrm{III}}$ at $5,850 \mathrm{~nm}$ after onset of a $300 \mathrm{~ms}$ photolysis laser pulse $a$ in $\mathrm{H}_{2}^{16} \mathrm{O}, b \mathrm{H}_{2}^{18} \mathrm{O}$ (inset spectral trace after 5 laser pulses), $c \mathrm{D}_{2} \mathrm{O}$, $d$ control experiment, no $\mathrm{Co}_{3} \mathrm{O}_{4}$ present. Red superoxide bands, blue $\mathrm{SO}_{4}{ }^{2-}$ growth (reduced acceptor). b Co ${ }^{\mathrm{IV}}=\mathrm{O}$ intermediate in $a \mathrm{H}_{2}^{16} \mathrm{O}$, $b \mathrm{H}_{2}^{18} \mathrm{O}, c \mathrm{D}_{2} \mathrm{O}$. c Isotopic composition of $\mathrm{O}_{2}$ gas accumulated in headspace of $\mathrm{H}_{2}^{18} \mathrm{O}$ solution measured by mass spectroscopy. d Temporal behavior of superoxide (black) and $\mathrm{Co}^{\mathrm{IV}}=\mathrm{O}$ intermediate (red). From Ref. 32, with permission in an aqueous suspension of $\mathrm{Co}_{3} \mathrm{O}_{4}$ nanocrystals placed on a diamond ATR element with 3 infrared reflections. Image a is from Ref. 33, with permission

interacts with two Co centers [32, 34]. A modest D isotope shift of $38 \mathrm{~cm}^{-1}$ in $\mathrm{D}_{2} \mathrm{O}$ to lower frequencies (band at $975 \mathrm{~cm}^{-1}$, Fig. 4Ac) signals hydrogen bonding interaction of the superoxide moiety, most likely with an adjacent $\mathrm{CoOH}(\mathrm{CoOD})$ group. As shown in Fig. 4D, this 3-electron oxidation intermediate, which is just one charge transfer step short of liberating $\mathrm{O}_{2}$, grows mostly during the $300 \mathrm{~ms}$ light pulse and as long as oxidized sensitizer species persist, but barely changes intensity afterwards. Evidently, arrival of another charge (hole) by continued illumination is required for the elimination of $\mathrm{O}_{2}$ and restart of the catalytic cycle, as illustrated in the proposed catalytic scheme of Fig. 5. At the same time, electrochemical measurements with an $\mathrm{O}_{2}$-sensitive Clark electrode indicate evolution of $\mathrm{O}_{2}$ in response to such a $300 \mathrm{~ms}$ light pulse. Mass spectroscopic analysis of the gas accumulated in the head space of the reaction vessel when using pure $\mathrm{H}_{2}^{18} \mathrm{O}$ showed a ratio of ${ }^{18} \mathrm{O}_{2}$ to ${ }^{18} \mathrm{O}^{16} \mathrm{O}$ of $8: 1$, with no unlabeled ${ }^{16} \mathrm{O}_{2}$ detected (Fig. 4C). The isotopic composition of the final $\mathrm{O}_{2}$ product agreed with the composition of the superoxide intermediate after a mere $1,500 \mathrm{~ms}$ illumination (Fig. 4Ab, inset), which confirms that the surface superoxide species is a kinetically competent intermediate of the $\mathrm{O}_{2}$ evolving catalytic cycle. Moreover, the complete absence of unlabeled superoxide and ${ }^{16} \mathrm{O}_{2}$ gas product in the $\mathrm{H}_{2}^{18} \mathrm{O}$ experiment indicates that the $\mathrm{OO}$ bond forming step involves attack by a water molecule from solution rather than direct coupling of two surface $\mathrm{O}$ of $\mathrm{Co}_{3} \mathrm{O}_{4}$ particles, a mechanistic question of much current interest in the field of water oxidation catalysis.

A second intermediate was detected at $840 \mathrm{~cm}^{-1}$, which does not exhibit an ${ }^{18} \mathrm{O}$ or $\mathrm{D}$ isotope shift. In contrast to the superoxide intermediate, the $840 \mathrm{~cm}^{-1}$ species decays spontaneously with a time constant of $1 \mathrm{~s}$ (Fig. 4B, D). The band is attributed to a $\mathrm{Co}^{\mathrm{IV}}=\mathrm{O}$ intermediate formed by oxidation of an octahedral $\mathrm{Co}{ }^{\mathrm{III}} \mathrm{OH}$ surface site in the first electron transfer step [32]. The spontaneous decay is assigned to $\mathrm{O}-\mathrm{O}$ chemical bond formation upon 

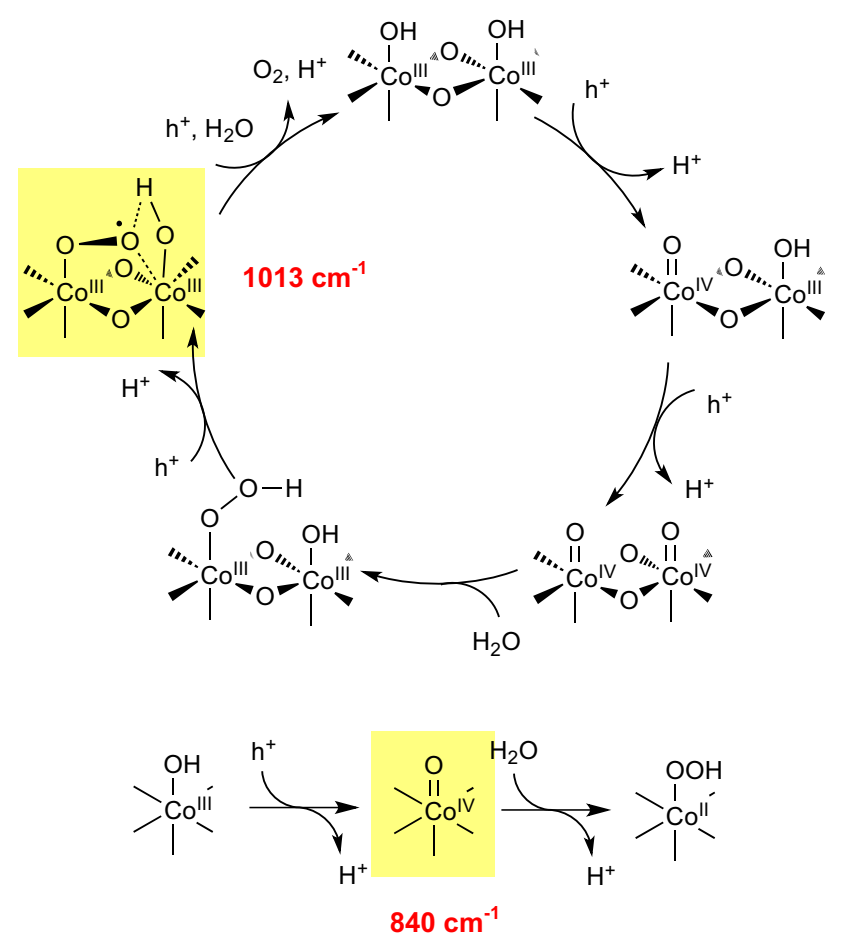

Fig. 5 Proposed catalytic mechanism of water oxidation on $\mathrm{Co}_{3} \mathrm{O}_{4}$ surface. Top Fast $\mathrm{Co}_{3} \mathrm{O}_{4}$ surface site. Bottom Slow $\mathrm{Co}_{3} \mathrm{O}_{4}$ surface site. The $\mathrm{OO}$ bond-forming step with $\mathrm{H}_{2} \mathrm{O}$ in the fast cycle features the cooperative effect of adjacent electronically coupled $\mathrm{Co}^{\mathrm{IV}}=\mathrm{O}$ sites, which is absent in the $\mathrm{H}_{2} \mathrm{O}$ addition reaction at the slow site. From Ref. 32, with permission

nucleophilic attack of $\mathrm{H}_{2} \mathrm{O}$ to yield $\mathrm{Co}^{\mathrm{II}} \mathrm{OOH}$ hydroperoxide intermediate (Fig. 5). Because the reaction time of $1 \mathrm{~s}$ is much slower than the rise of the superoxide intermediate (Fig. 4D), the $840 \mathrm{~cm}^{-1} \mathrm{Co}^{\mathrm{IV}}=\mathrm{O}$ site cannot be a precursor of the observed superoxide. Rather, the $840 \mathrm{~cm}^{-1}$ surface species belongs to a much slower catalytic site of $\mathrm{O}_{2}$ generation. While $\mathrm{Co}^{\mathrm{IV}}=\mathrm{O}$ has not been detected by vibrational spectroscopy before, Nocera and Britt have reported observation of the functionality by ex situ EPR measurement after electrochemical water oxidation at a Co oxide catalyst obtained by electrodeposition from a Co phosphate solution (Sect. 2.3) [35].

To identify the structural differences between the fast site that generates a superoxide intermediate and releases $\mathrm{O}_{2}$ within $300 \mathrm{~ms}$ of driving the $\mathrm{Co}_{3} \mathrm{O}_{4}$ catalyst by visible light sensitization, and the slow site that advances merely to the $\mathrm{Co}^{\mathrm{IV}}=\mathrm{O}$ state and then reacts with $\mathrm{H}_{2} \mathrm{O}$, the various crystal surfaces of $\mathrm{Co}_{3} \mathrm{O}_{4}$ and insights from Pourbaix analyses of $\mathrm{Co}$ oxides reported in the literature were considered. Pourbaix analysis of electrodeposits of Co oxide showed that the most active structural phase, formed at applied electrochemical potentials sufficient for $\mathrm{O}_{2}$ evolution from water, is a layered double hydroxide [36]. The prevalent motif of this structure consists of adjacent octahedral Co centers each with an $\mathrm{OH}$ group, linked by oxo bridges [36]. Because all crystallographic facets of $\mathrm{Co}_{3} \mathrm{O}_{4}$ have octahedrally coordinated $\mathrm{Co}^{\mathrm{III}}$ centers linked by an oxo bridge [37], $\mathrm{OH}$ terminated surfaces feature many sites with this same $\mathrm{Co}^{\mathrm{III}}(\mathrm{OH})-\mathrm{O}-\mathrm{Co}^{\mathrm{III}} \mathrm{OH}$ motif. Therefore, we propose that the fast catalytic site consists of two adjacent octahedral $\mathrm{Co}^{\text {III }}$ centers coupled by an oxo bridge, each with an $\mathrm{OH}$ ligand. Following oxidation of the two $\mathrm{Co}^{\mathrm{III}} \mathrm{OH}$ centers to adjacent $\mathrm{Co}^{\mathrm{IV}}=\mathrm{O}$ sites by two sequential holes, nucleophilic attack of a water molecule produces a $\mathrm{CoOOH}$ (hydroperoxide) functionality under reduction of both Co centers to $\mathrm{Co}^{\mathrm{III}}$ in a spin allowed, near-geometry conserving process (Fig. 5, top). Oxidation by a subsequent hole generates the observed superoxide surface intermediate, and yet another hole expels $\mathrm{O}_{2}$ and restarts the cycle. Hence, the TOF of the fast site is at least $3 \mathrm{~s}^{-1}$, which is over 150 times faster than the estimated average rate per surface Co. On the other hand, the slow site $\left(840 \mathrm{~cm}^{-1}\right.$ band) is proposed to originate from oxidation of an octahedral $\mathrm{Co}{ }^{\mathrm{III}} \mathrm{OH}$ group that is not linked to another $\mathrm{Co}^{\mathrm{III}} \mathrm{OH}$ site, leading to an isolated $\mathrm{Co}^{\mathrm{IV}}=\mathrm{O}$ instead (Fig. 5, bottom). Without the additional driving force imparted by an electronically coupled second $\mathrm{Co}^{\mathrm{IV}}=\mathrm{O}$ and a spin flip imposed by reduction to $\mathrm{Co}^{\mathrm{II}}$, a much slower $\mathrm{O}-\mathrm{O}$ bond forming step is expected, as observed.

These molecularly defined surface intermediates, observed here for the first time for water oxidation by an Earth abundant metal oxide catalyst under reaction conditions, provide the knowledge needed for modifying catalysts to enhance efficiency. Specifically, ideas can now be developed for increasing the density of octahedrally coordinated $\mathrm{Co}^{\mathrm{III}}(\mathrm{OH})-\mathrm{O}-\mathrm{Co}^{\mathrm{III}} \mathrm{OH}$ sites on Co oxide surfaces, which at this point has emerged as the most critical factor for accelerating the catalytic cycle.

\subsection{Electronic Structure of Metal Surface Centers Monitored by X-ray Spectroscopy}

The central role of oxo-bridged octahedral $\mathrm{Co}(\mathrm{OH})-\mathrm{O}-$ $\mathrm{CoOH}$ sites in the widely studied Co oxide electrodeposits from $\mathrm{Co}^{2+}$ solutions in phosphate electrolyte introduced by Nocera and his colleague [38] was recognized by combined electrokinetic and cyclic voltammetry studies. Specifically, a fast, one-electron, one-proton equilibrium which precedes the $\mathrm{O}-\mathrm{O}$ bond forming reaction is attributed to $\mathrm{Co}^{\mathrm{III}}(\mathrm{OH})-\mathrm{O}-\mathrm{Co}^{\mathrm{IV}}=\mathrm{O} \rightarrow \mathrm{Co}^{\mathrm{IV}}(=\mathrm{O})-\mathrm{O}-\mathrm{Co}^{\mathrm{IV}}=\mathrm{O}$ conversion [39]. Ex situ electron paramagnetic resonance spectroscopy (EPR) of these electrocatalytic films after reaction showed the buildup of $\mathrm{Co}^{\mathrm{IV}}=\mathrm{O}$ sites by a $\mathrm{g}_{\text {eff }}=2.27$ signal characteristic for $\mathrm{Co}^{\mathrm{IV}}(\mathrm{S}=1 / 2)$ (Fig. 6a) [35]. Moreover, a shift towards higher energy of the X-ray absorption near edge structure (XANES) of the 
(a)

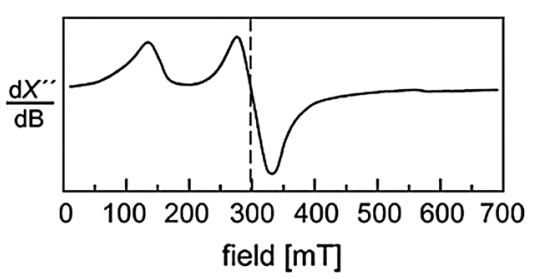

(b)

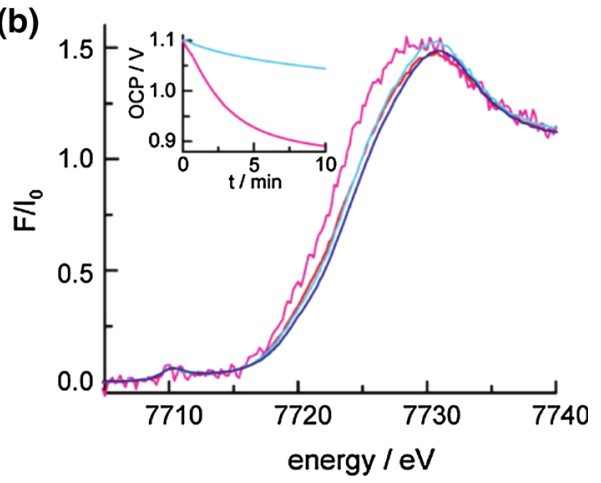

Fig. 6 Spectroscopy of electrodeposited Co oxide catalytic film. a Ex situ EPR spectrum $(4 \mathrm{~K})$ of a Co oxide film that was exposed to an applied potential of $1.34 \mathrm{~V}$ showing the $\mathrm{Co}^{\mathrm{IV}}$ signal. From Ref. 35, with permission. b XANES spectra of Co oxide film recorded in situ during electrocatalytic water oxidation showing surface at open circuit potential (magenta) and $1.25 \mathrm{~V}(\mathrm{red})$. As reference, bulk Co oxide film at open circuit potential (cyan) and $1.25 \mathrm{~V}$ (blue) are shown. From Ref. 40, with permission

Co K-edge was observed during electrocatalytic water oxidation, indicating that the oxidation state of some fraction of Co centers rises to IV under steady state conditions (Fig. 6b) [40]. These EPR and X-ray spectroscopic signals report on the electronic state of the metal center, thereby complementing the chemical bond information during the catalytic cycle that can be obtained by temporally resolved FT-IR spectroscopy. Future time resolved (pulsed) EPR and transient X-ray spectroscopy studies on such systems will likely provide new mechanistic insights about the precise electronic structure of the metal centers at each step of the catalytic cycle. This is particularly important in light of possible extensive charge delocalization across multiple Co centers as suggested by recent multi-frequency EPR studies of a $\mathrm{Co}_{4}\left(\mathrm{III}^{3}, \mathrm{IV}\right) \mathrm{O}_{4}$ oxobridged Co cubane model compound [41]. For understanding the dynamics of the wider domain structure of Co oxide electrodeposits under catalytic conditions which may influence reaction pathways, pair distribution function analysis of X-ray scattering probes longer range distances not accessible by EXAFS spectroscopy. The recent finding by Tiede based a study of an amorphous Co oxide electrocatalyst that distorted coordination geometries may contribute to catalytic activity demonstrates the important role of this technique [42, 43].

While no transient surface intermediates of (dark) electrochemically driven water oxidation on Co oxide films have been reported, structural phase transformations have been uncovered in the case of $\mathrm{Co}_{3} \mathrm{O}_{4}$ when tuning the applied potential towards levels needed for initiating catalysis. It is known from Pourbaix analysis that at an applied potential of $+0.75 \mathrm{~V}(\mathrm{NHE}, \mathrm{pH} 7)$ the $\mathrm{Co}_{3} \mathrm{O}_{4}$ spinel phase transforms reversibly to the Co oxy hydroxide phase $(\mathrm{Co}(\mathrm{O}) \mathrm{OH})$ [44]. In situ Raman [45] and X-ray spectroscopy [46] afford direct monitoring of the structural change, with results in agreement with theory [47, 48]. Knowledge of the structural phase of the oxide catalyst at the onset of catalytic activity is an important step towards learning about the detailed mechanism.

\subsection{Molecular Metal Oxide Analogues Contributing to Mechanistic Understanding}

Mechanistic comparisons of solid metal oxide catalysts with molecular polynuclear metal oxo analogues, where available, provide valuable insights. Molecular catalysts for water oxidation range from all-inorganic polyoxometalate clusters featuring a Co oxide core $\left[\mathrm{Co}_{4}\left(\mathrm{H}_{2} \mathrm{O}\right)_{2}\left(\mathrm{PW}_{9} \mathrm{O}_{34}\right)_{2}\right]^{10-}$ [49] to a variety of organometallic complexes involving late transition metals. Spectroscopic observations that provide interesting comparisons with the $\mathrm{Co}_{3} \mathrm{O}_{4}$ catalyst are available in particular for $\mathrm{Ru}$ based $\mathrm{O}_{2}$ evolving catalysts. For example, in the case of the extensively studied water oxidation catalyst $c i s, c i s-\left[(\text { bpy })_{2}\left(\mathrm{H}_{2} \mathrm{O}\right) \mathrm{Ru}^{\mathrm{III}} \mathrm{ORu}{ }^{\mathrm{III}}\left(\mathrm{H}_{2} \mathrm{O}\right)(\text { bpy })_{2}\right]^{4+}$ with a Ru-O-Ru core ('blue dimer'), a $\mathrm{Ru}^{\mathrm{V}}(=\mathrm{O}) \mathrm{ORu}^{\mathrm{V}}(=\mathrm{O})$ intermediate was found to undergo $\mathrm{O}-\mathrm{O}$ bond formation by nucleophilic attack of $\mathrm{H}_{2} \mathrm{O}$ to yield a hydroperoxide intermediate

$$
\begin{aligned}
& \mathrm{Ru}^{\mathrm{V}}(=\mathrm{O}) \mathrm{ORu}^{\mathrm{V}}(=\mathrm{O})+\mathrm{H}_{2} \mathrm{O} \rightarrow \mathrm{Ru}^{\mathrm{IV}}(\mathrm{OH}) \mathrm{ORu}^{\mathrm{IV}} \mathrm{OOH} \\
& \quad \rightarrow \mathrm{Ru}^{\mathrm{V}}(=\mathrm{O}) \mathrm{ORu}{ }^{\mathrm{III}} \mathrm{OOH}+\mathrm{H}^{+}(1)
\end{aligned}
$$

Both protonated and deprotonated form of the intermediate are directly observed by pairs of optical absorptions at $451,750 \mathrm{~nm}$ and $482,850 \mathrm{~nm}$, respectively [50, 51]. This hydroperoxide forming step (1) is analogous to the $\mathrm{O}-\mathrm{O}$ bond forming step $\mathrm{Co}^{\mathrm{IV}}(=\mathrm{O}) \mathrm{OCo}^{\mathrm{IV}}=\mathrm{O} \rightarrow$ $\mathrm{Co}^{\mathrm{III}}(\mathrm{OH}) \mathrm{OCo}^{\mathrm{III}} \mathrm{OOH}$ proposed for the $\mathrm{Co}_{3} \mathrm{O}_{4}$ catalyst and demonstrates the accelerating effect of adjacent, electronically coupled high valence oxo centers for $\mathrm{O}-\mathrm{O}$ bond formation. Single center Ru molecular catalysts are capable of evolving $\mathrm{O}_{2}$ evolution from water as well $[52,53]$. Optical and resonance Raman spectra of water oxidation intermediates of a mononuclear Ru polypyridyl complex obtained by electrochemical, stopped-flow and nanosecond pulse radiolysis experiments gave structural and kinetic insights on intermediates supported by theory that provided an early precedent for a single high valent metal oxo attacking $\mathrm{H}_{2} \mathrm{O}$ to form an $\mathrm{O}-\mathrm{O}$ bond [54]. Very recently, a mononuclear organo Co complex was shown to oxidize water by forming the 
$\mathrm{O}-\mathrm{O}$ bond by nucleophilic attack of $\mathrm{H}_{2} \mathrm{O}$ on a $\mathrm{Co}^{\mathrm{IV}}-\mathrm{OH}$ moiety [55], closely reflecting the proposed mechanism for single $\mathrm{Co}^{\mathrm{IV}}=\mathrm{O}$ sites on the $\mathrm{Co}_{3} \mathrm{O}_{4}$ surface (Fig. 5).

\section{Mn Oxide Water Oxidation Catalysts}

Manganese oxides have received particular attention as catalysts for water oxidation for a long time, in part because of the unique role of this oxide in the natural photosystem in the form of the $\mathrm{CaMn}_{4} \mathrm{O}_{4}$ cluster [20].

\subsection{Nanostructuring for High Turnover Frequency}

Similar to the case of Co oxides, there is a history of the use of $\mathrm{Mn}$ oxides as anode coatings for electrocatalytic water oxidation, typically under high $\mathrm{pH}$ conditions [13]. Yet the early reports suggested that $\mathrm{Mn}$ oxides hold promise for sufficiently fast water oxidation catalysts under mild $\mathrm{pH}$ conditions as well if nano-sized clusters with high surface area can be made. Using the same approach as in the case of $\mathrm{Co}_{3} \mathrm{O}_{4}$ of substantially increasing the number of metal surface centers of $\mathrm{Mn}$ oxide particles by nanostructuring, we explored crystalline Mn oxide nanostructured clusters in mesoporous silica scaffolds [18, 19]. Synthesis of highly nanostructured $\mathrm{Mn}$ oxide clusters of spherical shape in silica material of type KIT-6 with its 3-dimensional network of $8 \mathrm{~nm}$ diameter channels gave efficient water oxidation catalysts under close to neutral $\mathrm{pH}$ conditions. Figure 7a shows a TEM image of nanostructured $\mathrm{Mn}$ oxide clusters inside a KIT-6 scaffold ( $8 \%$ wt loading). The clusters of $80 \mathrm{~nm}$ diameter with narrow size distribution replicate the internal KIT-6 mesopore support structure, which remains intact even after calcination at high temperature. Mn K-edge X-ray absorption spectroscopy provided detailed information on the atomic structure of the clusters, exploiting the fact that the K-edge position depends linearly on the Mn oxidation state (shift to higher energy with increasing oxidation state). As shown in Fig. $7 b$, the average oxidation state varies with calcination temperature, which allowed us to determine the structural composition that gave the highest catalytic activity. A component analysis study of the XANES signal based on reference spectra of $\beta-\mathrm{MnO}_{2}, \alpha-\mathrm{Mn}_{2} \mathrm{O}_{3}$, and $\mathrm{Mn}_{3} \mathrm{O}_{4}$ revealed the fractional composition of the mixed-phase catalyst for each calcination temperature [19].

The cluster with the highest water oxidation activity as measured by the visible light sensitization method $\left(\left[\mathrm{Ru}(\text { bpy })_{3}\right]^{2+}-\mathrm{S}_{2} \mathrm{O}_{8}{ }^{2-}\right.$ system) discussed above (Sect. 2.1) showed TOF $=3,330 \mathrm{O}_{2} \mathrm{~s}^{-1}$ and consists of $\mathrm{Mn}_{2} \mathrm{O}_{3}$ as the dominant phase $(80 \%)$, with $\mathrm{MnO}_{2}(14 \%)$ and $\mathrm{Mn}_{3} \mathrm{O}_{4}$ $(6 \%)$ as minor phases. No degradation of activity or structural integrity of the Mn oxide nanoclusters was noted upon several hours of $\mathrm{O}_{2}$ evolution according to the XANES spectra and ICP analysis of the solution after photolysis, indicating reasonable stability under mild $\mathrm{pH}$ conditions. Taking into account the geometrical area of the Mn oxide nanocluster projected on a plane, we calculate $\mathrm{TOF}=$ $0.6 \mathrm{~s}^{-1} \mathrm{~nm}^{-2}$ projected area, not far from the $1 \mathrm{~s}^{-1} \mathrm{~nm}^{-2}$ value for $\mathrm{Co}_{3} \mathrm{O}_{4}$ nanocluster catalysts. Therefore, the nanostructured Mn oxide clusters supported by the KIT-6 mesoporous silica constitute an environmentally friendly, stable inorganic catalyst operating under mild aqueous conditions and modest overpotential $(350 \mathrm{mV})$. The silica environment may play an important role in preventing the surface of the metal oxide catalyst from restructuring, in addition to providing a stable dispersion that prevents agglomeration of the catalyst particles over time. The large effect of surface area enlargement by nanostructuring on the water oxidation efficiency was recently confirmed by a direct comparison of various $\mathrm{Mn}$ oxide morphologies in the absence of a supporting silica scaffold [56].
Fig. 7 Nanostructured Mn oxide cluster catalyst inside mesoporous silica KIT-6. a TEM image of cluster prepared by calcination at $800{ }^{\circ} \mathrm{C}$. b Average oxidation state of Mn for Mn oxide nanoclusters prepared at different calcination temperature, derived from K-edge energies. From Ref. 19, with permission (a)

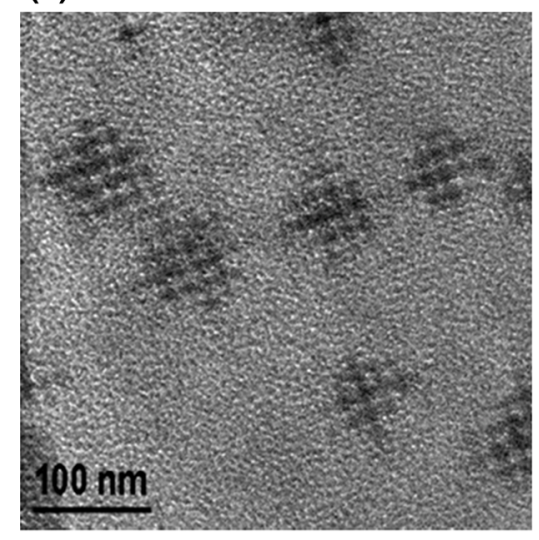

(b)

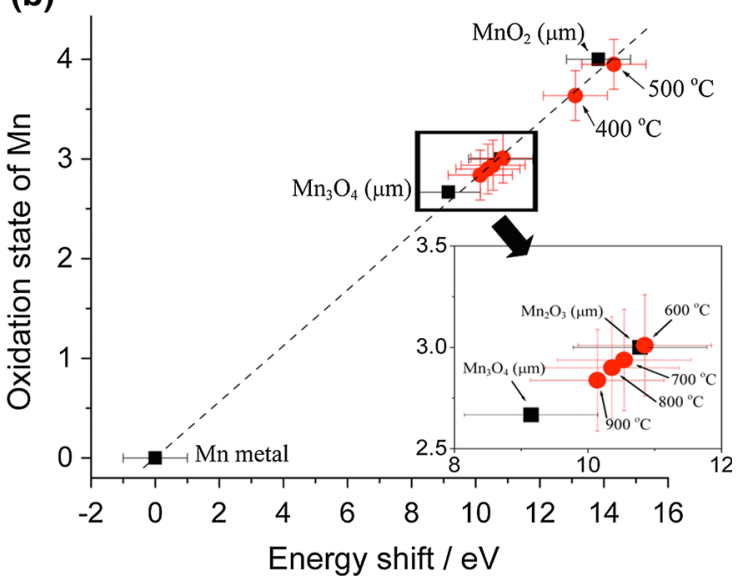


3.2 Mn Electronic State Monitored In Situ by Optical and X-ray Spectroscopy

Optical monitoring of water oxidation catalysis at $\mathrm{MnO}_{2}$ nanoparticles driven electrochemically has recently provided the first observation of intermediate species formed on the catalyst surface [57]. As shown in Fig. 8, an optical absorption band with a maximum at $510 \mathrm{~nm}$ is detected by diffuse transmission spectroscopy at the aqueous-solid interface of a $\delta-\mathrm{MnO}_{2}$ nanoparticle film attached to a transparent oxide anode (fluorine doped tin oxide, FTO) at potentials of $1.2 \mathrm{~V} \mathrm{SHE}$ and higher. At this threshold potential, $\mathrm{O}_{2}$ evolution is observed. The band is assigned to the $\mathrm{d}-\mathrm{d}$ transition of $\mathrm{Mn}^{3+}$ centers, which was corroborated by the use of a chemical probe [57]. However, the chemical functionality of the surface site associated with the $\mathrm{Mn}^{3+}$ signal awaits identification by a structure specific spectroscopy, which will be required for determining the role of the intermediate in the catalytic water oxidation cycle.

For another type of Mn oxide catalyst electrodeposited on a $\mathrm{Au} / \mathrm{Ti}$ electrode suitable for in situ X-ray absorption spectroscopy (XANES and EXAFS) under electrocatalytic conditions, Jaramillo and coworkers have identified distinct structural phases present under water oxidation and oxygen reduction conditions for one and the same electrodeposit $[58,59]$. The XANES spectrum of the Mn oxide catalyst film measured under $\mathrm{O}_{2}$ reduction conditions $(0.7 \mathrm{~V}$ RHE, pH 13), shown in Fig. 9a agrees well with that of a $\mathrm{Mn}_{3} \mathrm{O}_{4}$ reference sample whose structure is depicted in Fig. 10a. The shift of the K-edge to lower energy, Fig. 9a, signals reduction of the metal to $\mathrm{Mn}^{\mathrm{II}}$ with the observed edge energy closely matching the valence of 2.7 for $\mathrm{Mn}_{3} \mathrm{O}_{4}$. The structural assignment is further supported by comparison of Mn K-edge EXAFS measurements for the catalyst under $\mathrm{O}_{2}$ evolution conditions with $\mathrm{Mn}_{3} \mathrm{O}_{4}$ EXAFS data,

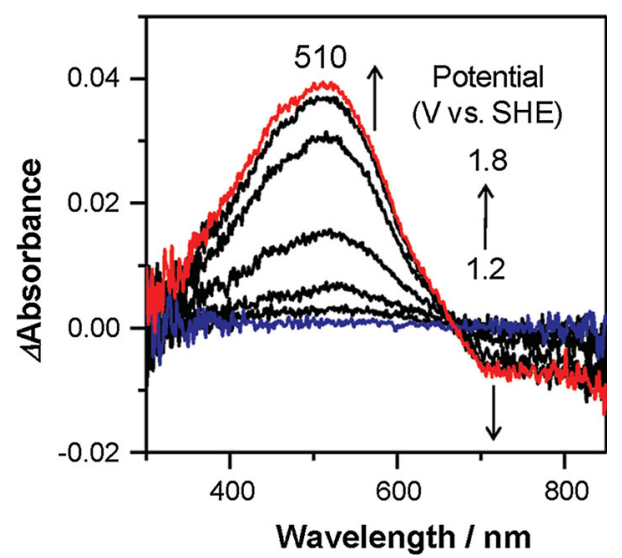

Fig. 8 Diffuse transmission optical absorption spectroscopy of Mn oxide nanoparticles under electrocatalytic conditions. Changes of the $\delta-\mathrm{MnO}_{2}$ film with increasing potential in the range 1.2-1.8 V SHE are shown. Spectra at 1.2 and $1.8 \mathrm{~V}$ are colored blue and red, respectively. From Ref. 57, with permission

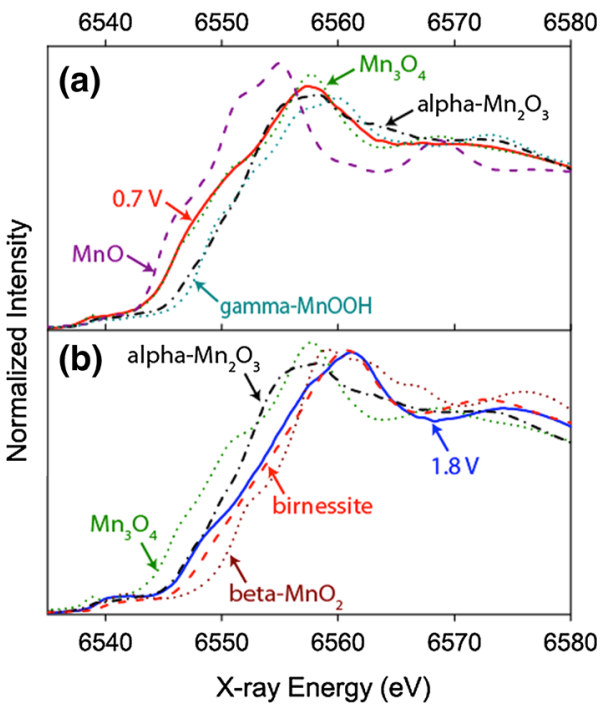

Fig. 9 XANES spectroscopy of Mn oxide catalytic film deposited on $\mathrm{Au} / \mathrm{Ti}$-electrode under reaction conditions. a $\mathrm{MnO}_{\mathrm{x}} / \mathrm{Au}-\mathrm{Si}_{3} \mathrm{~N}_{4}$ film poised at $0.7 \mathrm{~V}$ overlaid with reference materials $\mathrm{MnO}, \mathrm{Mn}_{3} \mathrm{O}_{4}$, $\alpha-\mathrm{Mn}_{2} \mathrm{O}_{3}$, and $\gamma-\mathrm{Mn}(\mathrm{O}) \mathrm{OH}$. b $\mathrm{MnO}_{\mathrm{x}} / \mathrm{Au}-\mathrm{Si}_{3} \mathrm{~N}_{4}$ film poised at $1.8 \mathrm{~V}$ overlaid with reference materials $\mathrm{Mn}_{3} \mathrm{O}_{4}, \alpha-\mathrm{Mn}_{2} \mathrm{O}_{3}$, birnessite, and $\beta-\mathrm{MnO}_{2}$. From Ref. 58, with permission

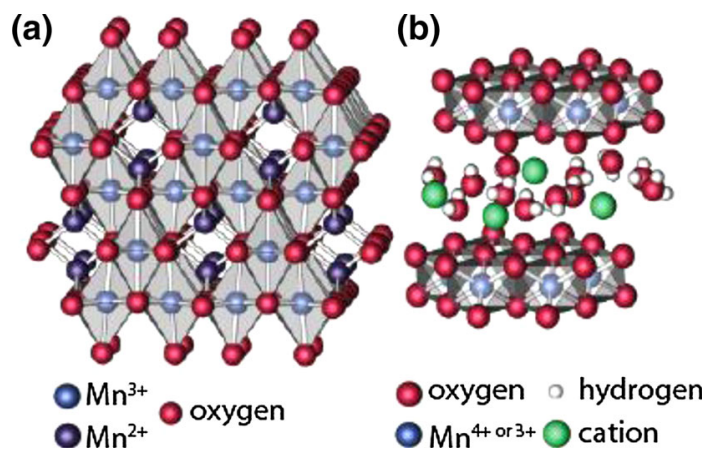

Fig. 10 Schematic showing crystal structures of a $\mathrm{Mn}_{3} \mathrm{O}_{4}$ consisting of octahedral (light blue) and tetragonal (dark blue) Mn sites. b Birnessite structure consisting of sheets of edge-sharing $\mathrm{MnO}_{6}$ octahedra with cations and water intercalated into the interlayer space. From Ref. 58, with permission

although the amplitudes of the sample are considerably lower due to polycrystallinity with small domain sizes of the electrodeposit (Fig. 11a). In contrast, the XANES profile of the same $\mathrm{MnO}_{\mathrm{x}}$ electrodeposit under water oxidation conditions (1.8 V RHE, $\mathrm{pH} 13$ ) shifts to higher energy and is similar to the $\alpha-\mathrm{Mn}_{2} \mathrm{O}_{3}$ phase (Fig. 9b). The profile most closely agrees with that of $\mathrm{H}^{+}$and $\mathrm{Mg}^{2+}$ birnessite phases with a layered structure and an average Mn oxidation state of 3.7 whose cartoon structure is shown in Fig. 10b. More accurately, composition analysis indicates birnessite $(80 \%)$ and $\mathrm{Mn}_{3} \mathrm{O}_{4}(20 \%)$ [58]. Agreement of the EXAFS traces of $\mathrm{Mg}^{+}$birnessite and the catalyst under $\mathrm{O}_{2}$ evolution conditions is excellent (Fig. 11b). 


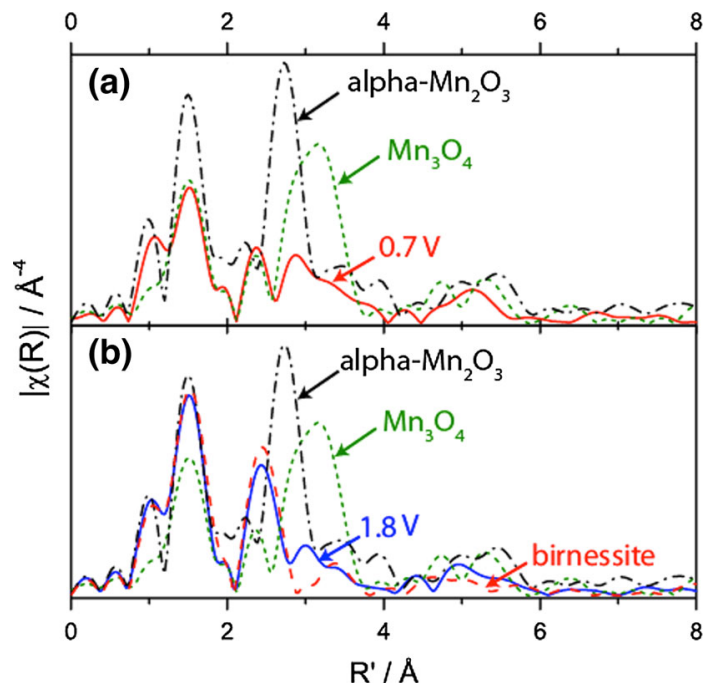

Fig. 11 EXAFS spectroscopy of Mn oxide catalytic film deposited on $\mathrm{Au} / \mathrm{Ti}$ electrode under reaction conditions. a $\mathrm{MnO}_{\mathrm{x}} / \mathrm{Au}-\mathrm{Si}_{3} \mathrm{~N}_{4}$ film poised at $0.7 \mathrm{~V}$ overlaid by reference materials $\mathrm{Mn}_{3} \mathrm{O}_{4}$ and $\alpha-\mathrm{Mn}_{2} \mathrm{O}_{3}$. b $\mathrm{MnO}_{\mathrm{x} /} \mathrm{Au}-\mathrm{Si}_{3} \mathrm{O}_{4}$ film poised at $1.8 \mathrm{~V}$ overlaid by reference materials $\mathrm{Mn}_{3} \mathrm{O}_{4}, \alpha-\mathrm{Mn}_{2} \mathrm{O}_{3}$, and birnessite. From Ref. 58, with permission

This first in situ observation of birnessite Mn oxide structure as the catalytically active phase under water oxidation conditions furnishes an important link to several recent reports of ex situ XANES measurements on other catalytically very active $\mathrm{Mn}$ oxide and $\mathrm{CaMnO}_{\mathrm{x}}$ preparations that reveal birnessite structure [21, 22, 60]. Surface chemical functionalities formed during the water oxidation cycle have not yet been observed for these Mn oxide catalysts, but knowledge of the structural phase during reaction is an important step towards a mechanistic understanding. The flexible layers of octahedral $\mathrm{MnO}_{6}$ of the birnessite structure surrounded by water (Fig. 10b) offer a very large surface for catalytic Mn sites interacting with $\mathrm{H}_{2} \mathrm{O}$ molecules.

\section{Ir Oxide Catalyst: Combining Bond Specificity of Infrared Spectroscopy with Metal Electronic Structure Specificity of XPS}

Ir oxide is the only known metal oxide catalyst for water oxidation that performs efficiently and stably in acid as well as base [61]. The oxide is used in commercial electrolyzers [62] and has been explored as a catalytic component in a various electrochemical cells [1, 63], photoanode assemblies [64] and integrated artificial photosystem designs [65, 66]. Large scale use of this noble metal oxide as water oxidation catalyst is prohibited by its scarcity, but mechanistic understanding will be valuable given the observed high efficiency. Direct absorption of light by $\mathrm{IrO}_{2}$ nanoparticles $(2 \mathrm{~nm})(\mathrm{Ir} \mathrm{d}-\mathrm{d}$ transition in the visible or $\mathrm{O}(\mathrm{p})-\operatorname{Ir}(\mathrm{d}(\mathrm{e} . \mathrm{g})$.$) charge transfer in the UV) in the$ presence of an electron acceptor is capable of inducing water oxidation (though inefficiently) and has provided insights into those electronic properties of the oxide that enable water oxidation catalysis [67]. Visible light-on/off rapid-scan FT-IR monitoring in the ATR mode (light pulse of $1 \mathrm{~s}$ duration) of an aqueous solution of Ir nanoparticles $(\mathrm{pH} \mathrm{6})$ in the presence of the $\left[\mathrm{Ru}(\mathrm{bpy})_{3}\right]^{2+}$ sensitizer and persulfate electron acceptor system showed a band at $830 \mathrm{~cm}^{-1}\left(\mathrm{H}_{2} \mathrm{O}\right)$ that only appeared during the light-on period, as shown in Fig. 12a [68]. The same experiments in $\mathrm{D}_{2}^{16} \mathrm{O}$ and $\mathrm{D}_{2}^{18} \mathrm{O}-\mathrm{D}_{2}^{16} \mathrm{O}$ isotopic mixtures revealed two bands with ${ }^{18} \mathrm{O}$ shifts of 25 and $50 \mathrm{~cm}^{-1}$, respectively, characteristic of ${ }^{18} \mathrm{O}-{ }^{16} \mathrm{O}$ and ${ }^{18} \mathrm{O}-{ }^{18} \mathrm{O}$ peroxide bond modes (Fig. 12b). A $30 \mathrm{~cm}^{-1} \mathrm{D}$ shift in $\mathrm{D}_{2} \mathrm{O}$ identified the intermediate as a surface hydroperoxide (IrOOH). The fact that the bands appear only during the laser pulse $(1 \mathrm{~s}$ duration) but vanish instantly when the light is off is consistent with the known TOF of $6-10 \mathrm{~s}^{-1}$ for $\mathrm{H}_{2} \mathrm{O}$ oxidation at $\mathrm{IrO}_{2}[63,69,70]$ and confirms that the intermediate is a kinetically relevant species of the catalytic water oxidation cycle [68]. The observed frequency of the OO mode does not allow us to identify the metal oxidation state of the IrOOH group. Nevertheless, based on the expectation that $\mathrm{IrOOH}$ is formed by nucleophilic attack of $\mathrm{H}_{2} \mathrm{O}$ on $\mathrm{Ir}^{\mathrm{V}}=\mathrm{O}$, the oxidation state is likely $\mathrm{Ir}^{\mathrm{III}} \mathrm{OOH}$ (OO bond formation by nucleophilic attack of $\mathrm{H}_{2} \mathrm{O}$ on an oxo group results in a formal 2-electron reduction of the metal). A recent ambient pressure XPS study of electrocatalytic water oxidation on $\mathrm{IrO}_{2}$ nanoparticles under steady state conditions by Nilsson indicates the formation of $\mathrm{Ir}^{\mathrm{V}}$ centers at catalyst surface [71]. Hence, with the direct observation of the hydroperoxide intermediate by FT-IR spectroscopy
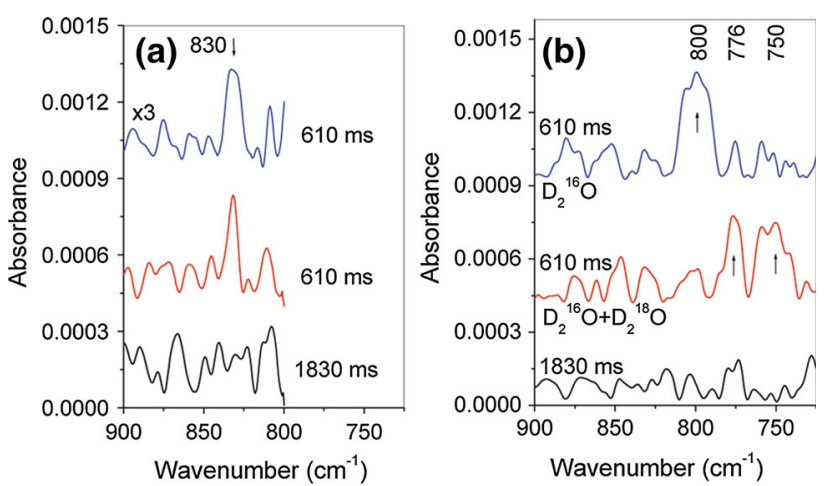

Fig. 12 Rapid-scan FT-IR spectra of IrOOH (hydroperoxide) surface intermediate of water oxidation at Ir oxide nanoparticle-aqueous solution interface. a $610 \mathrm{~ms}$ (photolysis light on) and $1,830 \mathrm{~ms}$ spectra (light off). b Top $610 \mathrm{~ms}$ time slices of experiments in $\mathrm{D}_{2}^{16} \mathrm{O}$. Middle $\mathrm{D}_{2}^{16} \mathrm{O}(33 \%)+\mathrm{D}_{2}^{18} \mathrm{O}(66 \%)$. Bottom $1,830 \mathrm{~ms}$ time slice (light off) of experiment in $\mathrm{D}_{2}^{16} \mathrm{O}$. From Ref. 68, with permission 


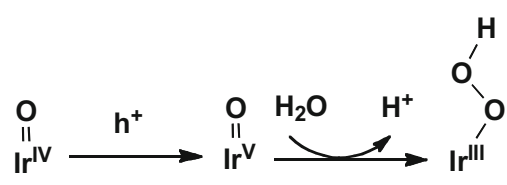

Fig. 13 Mechanism of OO bond forming step of water oxidation at Ir oxide surface. From Ref. 68, with permission

and the detection of $\operatorname{Ir}^{\mathrm{V}}$ by XPS in aqueous media under reaction conditions, key features of the catalytic cycle begin to emerge, allowing us to propose the partial mechanism shown in Fig. 13. A surface IrOOH intermediate on $\mathrm{IrO}_{2}(110)$ has been predicted by quantum chemical calculations [72]. Furthermore, an identical mechanism has been proposed for single Ir center molecular catalysts for water oxidation [73].

While the spectroscopic observations pertain only to the first (of four) charge transfer intermediates with the subsequent steps from $\mathrm{Ir}^{\mathrm{III}} \mathrm{OOH}$ to $\mathrm{O}_{2}$ still to be uncovered, these results, together with those of the $\mathrm{Co}_{3} \mathrm{O}_{4}$ study begin to establish the molecular identity of surface intermediates and detailed elementary reaction steps of water oxidation on metal oxide surfaces. Specifically, the findings confirm the dominant role of nucleophilic attack of $\mathrm{H}_{2} \mathrm{O}$ on an electrophilic oxo metal site in $\mathrm{O}-\mathrm{O}$ bond formation over a possible alternative path of direct coupling of adjacent oxo metal sites $\left(\mathrm{M}=\mathrm{O}+\mathrm{O}=\mathrm{M} \rightarrow \mathrm{O}_{2}+\mathrm{M}+\mathrm{M}\right)$ to liberate $\mathrm{O}_{2}$.

\section{$5 \mathrm{TiO}_{2}, \mathrm{SrTiO}_{3}$ and $\mathrm{Fe}_{2} \mathrm{O}_{3}$ Photocatalysts: Monitoring Light Induced Charge Flow Driving Chemical Transformations at the Catalyst Surface}

Some metal oxides, notably $\mathrm{TiO}_{2}, \mathrm{SrTiO}_{3}, \mathrm{Fe}_{2} \mathrm{O}_{3}$ and $\mathrm{WO}_{3}$ combine the light absorption, charge separation and catalytic function in a single crystalline material. Because of the built-in light absorption property, these systems offer the most straightforward approach for elucidating the elementary steps of charge transport across the oxide bulk to the catalyst surface and the subsequent processes that induce chemical reaction. In the case of films of $\mathrm{TiO}_{2}$ (rutile) particles $(30-50 \mathrm{~nm})$ exposed to aqueous solution under UV excitation, in situ steady state FT-IR spectroscopy in the ATR mode has revealed two surface intermediates, namely $\mathrm{TiOOH}$ and TiOOTi [74]. Figure 14a shows the growth of the $\mathrm{O}-\mathrm{O}$ stretch mode of the hydroperoxide intermediate $(\mathrm{TiOOH})$ with a maximum at $838 \mathrm{~cm}^{-1}$ in acidic solution ( $\mathrm{pH}$ 2.4) under continuous photolysis. Experiments were conducted as half reactions by using a sacrificial acceptor for capturing the $\mathrm{TiO}_{2}$ conduction band electrons before they can recombine with transient valence band holes. A second surface intermediate absorbing at
$812 \mathrm{~cm}^{-1}$ exhibits most pronounced growth over the first few minutes of photolysis and is dominant in alkaline solution ( $\mathrm{pH}$ 11.9), as shown in Fig. 14b. It is attributed to the $\mathrm{O}-\mathrm{O}$ stretch of a TiOOTi surface site. Spectral identification of both surface intermediates is supported by ${ }^{18} \mathrm{O}$ isotope labeling studies [74]. The proposed mechanism features hole transfer to a bridging $\mathrm{O}$ of a TiOTi surface moiety (note that hole capture by $\mathrm{Ti}^{\mathrm{IV}}$ metal centers is energetically not possible) followed by nucleophilic attack of $\mathrm{H}_{2} \mathrm{O}$ under concurrent breaking of a Ti-O bond. Coupling of adjacent $\mathrm{Ti}-\mathrm{O}$ radical sites is proposed to result in the observed TiOOTi site, as shown in Fig. 15. The formation of the surface hydroperoxide intermediate in acidic solution and its absence under basic conditions is explained by partial hydrolysis of the TiOOTi group at low $\mathrm{pH}$. Transfer of two additional holes liberates $\mathrm{O}_{2}$ and restarts the photocatalytic cycle.

Using transient optical absorption spectroscopy over the entire time range from picosecond to seconds, Durrant and coworkers have monitored the behavior of holes generated upon UV excitation of $\mathrm{TiO}_{2}$ (anatase) films. Transient holes with an absorption maximum at $460 \mathrm{~nm}$ with lifetimes of several seconds are detected and their kinetic behavior attributed to the rate-limiting water oxidation step of the catalytic cycle $[75,76]$. Cuk and coworkers, working with single crystal $n$ - $\mathrm{SrTiO}_{3}$ as a highly efficient photoanode for water oxidation, combined the tuning of an applied potential with surface sensitive ultrafast optical spectroscopy to selectively monitor the charge transport processes across the surface-Helmholtz layer interface of the alkaline solution under operating conditions [77]. As shown in Fig. 16, the time dependence of the optical absorption of the photo-generated valence band hole at $800 \mathrm{~nm}$ indicates a process with a single rate constant that has an exponential dependence on the surface hole potential (from $3 \mathrm{~ns}$ to 8 ps over a $1 \mathrm{~V}$ potential increase). This result implies a single hole transfer step initiating water oxidation and reveals the associated activation barrier. The process, which is assigned to oxidation of hydroxide ion to $\mathrm{OH}$ radical and observed here as a separate process for the first time, is set apart from all subsequent hole transfers, which are much slower [77]. In light of the infrared results [74] and the mechanism proposed in Fig. 15 (and ignoring the fact that $\mathrm{SrTiO}_{3}$ is used in the transient optical work), the subsequent slow process might be the formation of a $\mathrm{TiO}\left(\mathrm{h}^{+}\right) \mathrm{Ti}$ site. These results set the stage for temporally resolved infrared monitoring under reaction conditions for uncovering the chemical identity of the surface functionality that is formed.

Transient optical spectroscopic measurements at the widely investigated $\mathrm{Fe}_{2} \mathrm{O}_{3}$ (hematite) water oxidation catalyst reveal long-lived absorptions in the $600-800 \mathrm{~nm}$ region (milliseconds to seconds) upon bandgap excitation, 


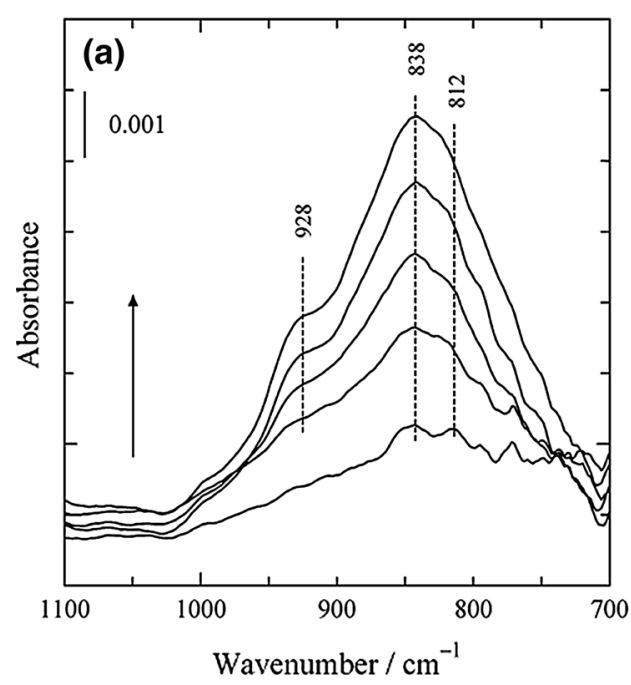

Fig. 14 FT-IR spectroscopy of $\mathrm{TiO}_{2}$ (rutile) particles in aqueous solution under photocatalytic conditions. a $\mathrm{TiO}_{2}$ film in contact with aqueous solution at $\mathrm{pH} 2.4$ recorded at $1,10,20,30,40 \mathrm{~min}$. After start of UV illumination. The arrow indicates the direction of the spectral change. $\mathrm{Fe}^{3+}$ was used as electron acceptor. b Solid traces

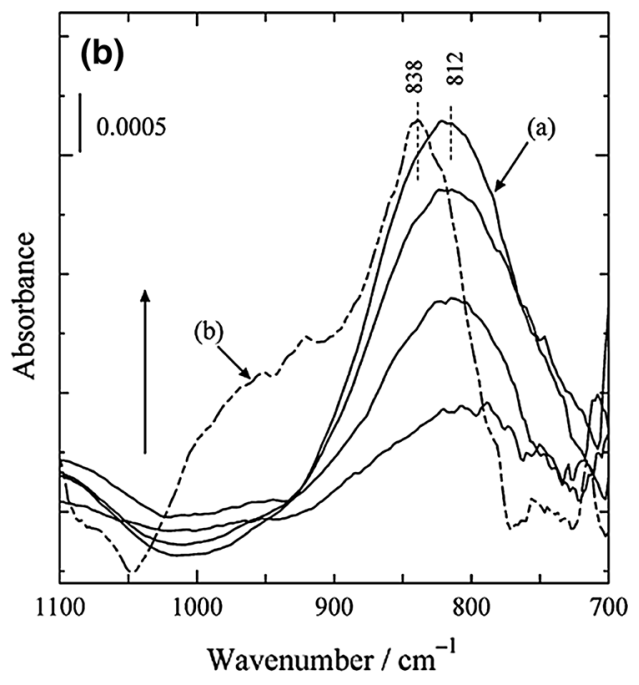

Identical illumination protocol as in a but in $\mathrm{pH} 11.9$ solution using loaded $\mathrm{Pt}$ particles as electron acceptor. Broken trace The $\mathrm{Pt} / \mathrm{TiO}_{2}$ sample was exposed to acidic ( $\mathrm{pH}$ 2.4) conditions after UV irradiation experiment, confirming that the $812 \mathrm{~cm}^{-1}$ species is unique for alkaline conditions. From Ref. 74, with permission
Fig. 15 Proposed reaction mechanism for photocatalytic water oxidation at $\mathrm{TiO}_{2}$ (rutile)—aqueous interface. From Ref. 74, with permission

Fig. 16 Transient optical spectroscopy of hole transport across $n-\mathrm{SrTiO}_{3}$ aqueous solution interface. a Schematic of processes that are probed. b Decay of photogenerated valence band holes probed at $800 \mathrm{~nm}$ as function of applied potential. From Ref. 77, with permission

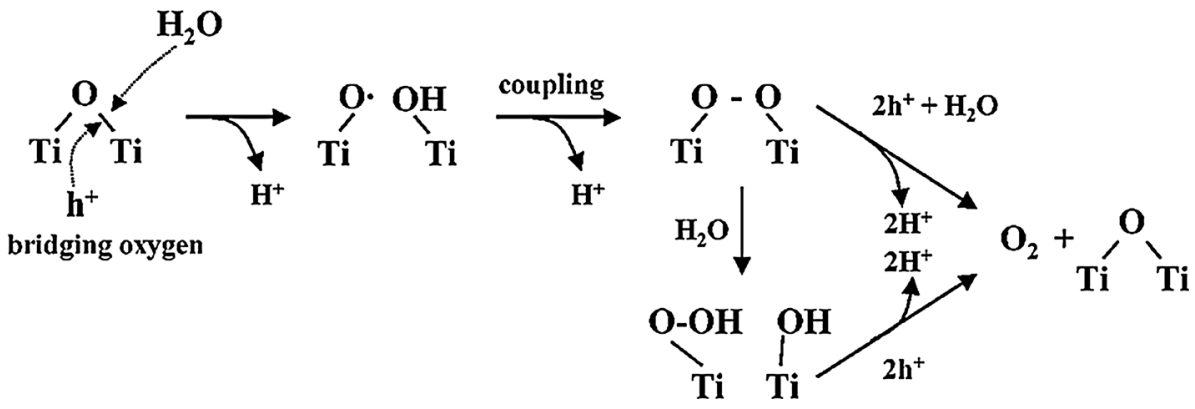

(a)

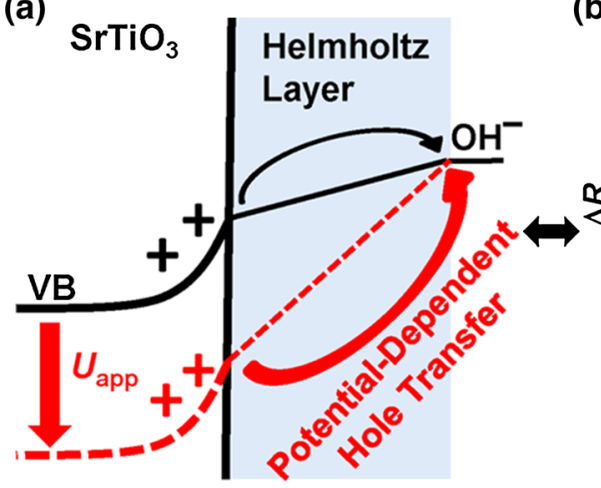

(b)

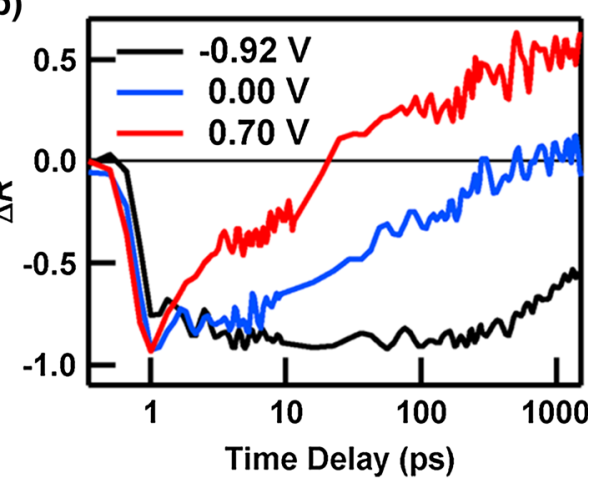

which are attributed to holes involved in the catalysis [78]. Identification of the surface chemical functionality by vibrational spectroscopy is not yet available and the mechanistic meaning of the signal is currently under debate. One proposed assignment is that of a high valent $\mathrm{Fe}^{\mathrm{V}}=\mathrm{O}$ surface intermediate that subsequently would undergo electrophilic attack $\mathrm{H}_{2} \mathrm{O}$ to yield a hydroperoxide intermediate [79]. There is convincing evidence for the same mechanism of $\mathrm{O}-\mathrm{O}$ bond formation for $\mathrm{O}_{2}$ evolving organo iron catalysts $[80,81]$.

Future investigations based on combined transient optical and transient vibrational spectroscopy on how 
transferred charges induce catalytic transformations on the metal oxide surface need to be expanded to systems in which light absorption and catalytic function are separated. Initial systems for which hole transport from light absorber to metal oxide catalyst has already been established by transient optical measurements (observed times are milliseconds or less, in some cases ultrafast) include $\mathrm{TiO}_{2}-\mathrm{IrO}_{2}$ [82], GaN: $\mathrm{ZnO}-\mathrm{CoO}_{\mathrm{x}}$ [83], $\left[\mathrm{Ru}(\mathrm{bpy})_{3}\right]^{2+}$-polyoxo-metalate $\left(\left[\left\{\mathrm{Ru}_{4} \mathrm{O}_{4}(\mathrm{OH})_{2}\left(\mathrm{H}_{2} \mathrm{O}\right)_{4}\right\}\left(\gamma-\mathrm{SiW}_{10} \mathrm{O}_{36}\right)_{2}\right]{ }^{10-}\right)$ [84], and $\left[\mathrm{Ru}(\mathrm{bpy})_{3}\right]^{2+}-\mathrm{IrO}_{2}[85]$.

\section{Closing the Catalytic Cycle of Water Oxidation at Metal Oxide Particle with Carbon Dioxide Reduction at Heterobinuclear Site}

Water oxidation to molecular oxygen is a mandatory reaction of any photosynthetic process because it provides the electrons and protons that enable the formation of a fuel upon reaction with carbon dioxide. As an example, we discuss here the coupling $\mathrm{O}_{2}$ evolution from water at a metal oxide catalyst with carbon dioxide reduction at an all-inorganic, oxo-bridged heterobinuclear light absorber [66].

Oxo-bridged, all-inorganic heterobinuclear units covalently anchored on a silica surface possess metal-to-metal charge-transfer (MMCT) absorptions that extend deep into the visible region. The optical absorption originates from the overlap of the d orbitals of the two metal centers. Units with appropriate redox potentials are capable of driving a water oxidation catalyst, others reduce $\mathrm{CO}_{2}$ to $\mathrm{CO}$ or formate. Todate, a dozen different systems featuring $\mathrm{Ti}$ or $\mathrm{Zr}$ as acceptor and a first or second row transition metal as donor center have been developed [86-97]. The detailed structure of several units on the surface of mesoporous silica supports, including the $\mathrm{ZrOCo}^{\mathrm{II}}$ system shown in
Fig. 17a has been determined by EXAFS spectroscopy [66, $96,97]$. Typical metal-to-metal distances are around $3.4 \mathrm{~A}$. The optical MMCT absorption $\mathrm{Zr}^{\mathrm{IV}} \mathrm{OCo}^{\mathrm{II}} \rightarrow \mathrm{Zr}^{\mathrm{III}} \mathrm{OCo}^{\mathrm{III}}$, shown in Fig. 17b, extends from the UV into the visible region with an onset around $550 \mathrm{~nm}$. The ability of most binuclear units to drive MMCT induced redox reactions is attributed to an unusually long lifetime of the excited charge transfer state which has its origin in ultrafast spin crossover after light absorption that results in slow back electron transfer. In the case of the TiOMn ${ }^{\mathrm{II}}$ system, the lifetime was determined as $2.4 \mu \mathrm{s}$ at room temperature by transient optical absorption spectroscopy [95, 98].

In an attempt to couple a metal oxide nanocatalyst for water oxidation with a heterobinuclear MMCT unit for accomplishing $\mathrm{CO}_{2}$ reduction by electrons donated by $\mathrm{H}_{2} \mathrm{O}$, we have developed a photodeposition method for coupling a binuclear light absorber to an Ir oxide nanocluster. The $\mathrm{ZrOCo}^{\mathrm{II}}$ unit was selected because it was found to reduce vapor phase $\mathrm{CO}_{2}$ to $\mathrm{CO}$ and formate upon visible or UV excitation of the charge transfer state in the presence of triethylamine as a sacrificial donor [97]. Since transient $\mathrm{Co}^{\mathrm{III}}$ center generated upon excitation of the MMCT state has an oxidation potential around $+1.8 \mathrm{~V}$, it should be possible to simultaneously drive a water oxidation catalyst with this unit. Development of a photodeposition method for proper positioning of an Ir oxide nanocluster catalyst adjacent to the Co donor center of a ZrOCo unit in the channels of mesoporous silica SBA-15 allowed us to synthesize polynuclear units consisting of a $\mathrm{ZrOCo}$ charge-transfer chromophore coupled to an $\mathrm{IrO}_{\mathrm{x}}$ nanocluster catalyst. The spatially directed assembly of the Ir oxide clusters was monitored by optical and FT-IR spectroscopy, and their size of the $2 \mathrm{~nm}$ established by HAADF-STEM imaging and EDX measurements [66].

When illuminating the MMCT absorption of $\mathrm{ZrOCo}^{\mathrm{II}}$ $\mathrm{IrO}_{\mathrm{x}}$ units supported on SBA-15 loaded with a gas mixture
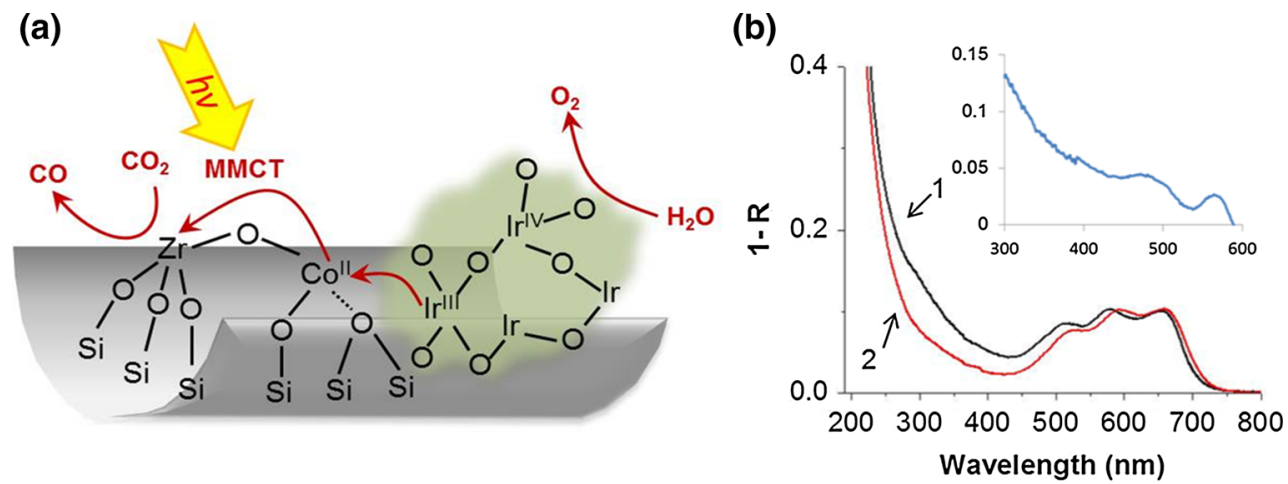

Fig. 17 Photosynthetic unit for $\mathrm{CO}_{2}$ reduction by $\mathrm{H}_{2} \mathrm{O}$ consisting of a binuclear $\mathrm{ZrOCo}^{\mathrm{II}}$ charge-transfer light absorber coupled to a $2 \mathrm{~nm} \mathrm{Ir}$ oxide nanocluster catalyst. a Schematic of assembly. b UV-Vis diffuse reflectance spectra of $\mathrm{ZrOCo}^{\mathrm{II}}$ unit anchored in the channels of

mesoporous silica SBA-15 (black trace 1). The red trace (2) shows the spectrum of isolated $\mathrm{Co}^{\mathrm{II}}$ centers anchored on SBA-15. Inset Difference spectrum $\mathrm{ZrOCo}^{\text {II }}$ minus $\mathrm{Co}^{\mathrm{II}}$ sample showing the metalto-metal charge-transfer absorption. From Ref. 97, with permission 
of ${ }^{13} \mathrm{CO}_{2}$ and $\mathrm{H}_{2} \mathrm{O}$ with $355 \mathrm{~nm}$ light, growth of ${ }^{13} \mathrm{CO}$ and $\mathrm{O}_{2}$ product was observed by in situ FT-IR spectroscopy and mass spectrometry, respectively. As shown in Fig. 18a, gas phase ${ }^{13} \mathrm{CO}$ product grew in linearly (a partial ro-vibrational spectrum is presented). The $\mathrm{CO}$ is formed inside the $8 \mathrm{~nm}$ diameter silica channels and desorbs into the gas phase with a $340 \mu$ s escape time according to a previous transient FT-IR study [99]. Oxygen gas is detected mass spectrometrically (Fig. 18b). When conducting the photochemical experiment with a mixture of ${ }^{13} \mathrm{C}^{16} \mathrm{O}_{2}$ and $\mathrm{H}_{2}^{18} \mathrm{O}$, isotopically labeled ${ }^{18} \mathrm{O}_{2}$ was detected as well (Fig. 18c), establishing water as the electron source for $\mathrm{CO}_{2}$ reduction. No $\mathrm{CO}$ or $\mathrm{O}_{2}$ product appeared when omitting $\mathrm{H}_{2} \mathrm{O}$, which further confirmed that water serves as electron source. Also, no $\mathrm{CO}$ or $\mathrm{O}_{2}$ was produced when conducting photolysis in the presence of all components but omitting the photo-deposition procedure for preparing the $\mathrm{IrO}_{\mathrm{x}}$ clusters. Hence, photodepositon is a required step for establishing charge transfer coupling between the Co donor of the light absorber and the Ir oxide catalyst. The observed conversion of $\mathrm{CO}_{2}$ to $\mathrm{CO}$ and $\mathrm{O}_{2}\left(\Delta \mathrm{G}^{\circ}=62 \mathrm{kcal} \mathrm{mol}^{-1}\right)$ with $\mathrm{H}_{2} \mathrm{O}$ as electron source under illumination with $355 \mathrm{~nm}$ photons is consistent with the energetics of the reaction and in agreement with our previous results on the corresponding oxidation and reduction half reactions [66]. The quantum efficiency is estimated at $17 \%$ assuming that there is no energy transfer between individual photocatalytic sites. This is the first observation of $\mathrm{CO}_{2}$ photoreduction by $\mathrm{H}_{2} \mathrm{O}$ at an all-inorganic polynuclear light absorber-catalyst assembly with a molecularly defined chromophore. The system shows that direct coupling of a metal oxide catalyst for water oxidation with an inorganic charge transfer chromophore for $\mathrm{CO}_{2}$ reduction is feasible, and opens up detailed exploration of elementary charge transfer and catalytic steps of the complete cycle with vibrational, optical and X-ray techniques.

\section{Conclusions}

The discovery of new nanostructured forms of first row transition metal oxides in the past several years, foremost of $\mathrm{Co}$ and $\mathrm{Mn}$ that function as remarkably active water oxidation catalysts has attracted the attention of a number of catalysis groups to the challenge of elucidating the stepby-step mechanisms of the four-electron transfer chemistry at the aqueous solution-solid interface. For $\mathrm{Co}_{3} \mathrm{O}_{4}$, bond modes of a superoxo and an oxo $\mathrm{Co}^{\mathrm{IV}}$ species were detected by infrared spectroscopy, with the role of the surface intermediates in the catalytic cycle identified by their temporal behavior under reaction conditions. Ex situ EPR measurements of Co oxide electrodeposits revealed the formation of $\mathrm{Co}^{\mathrm{IV}}$ surface species, and steady-state
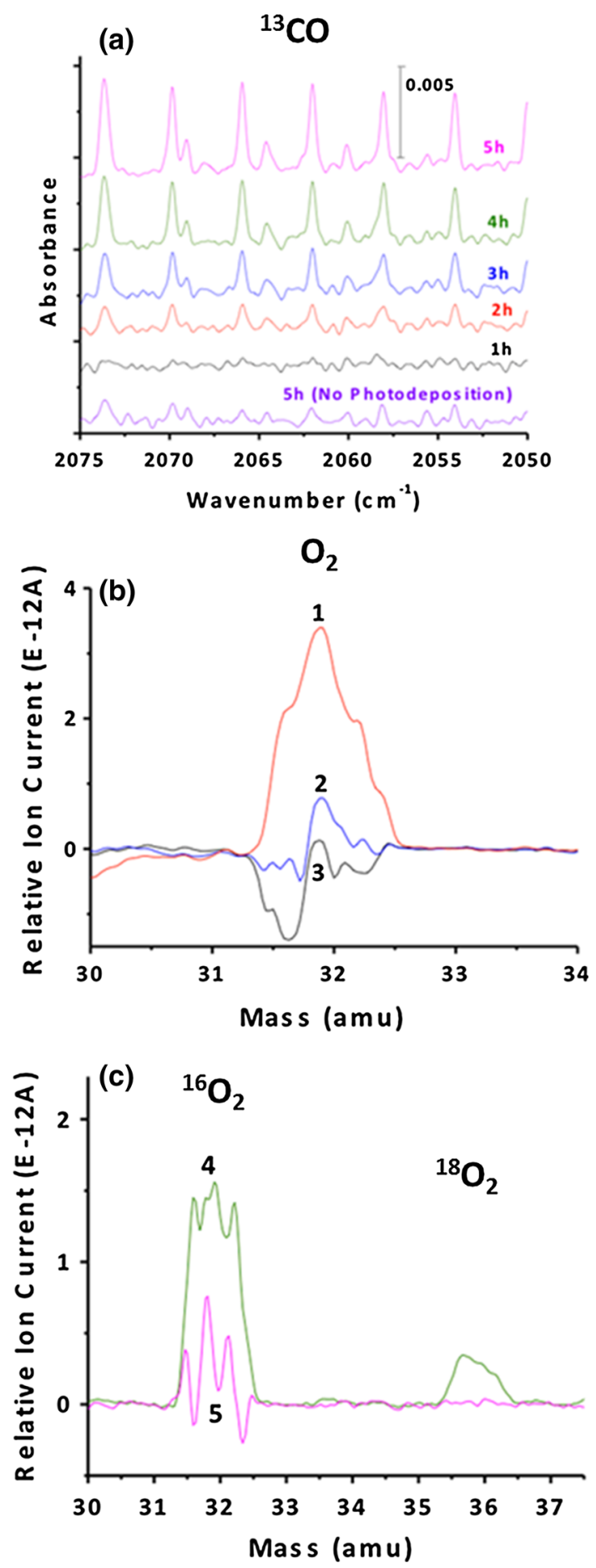

Fig. 18 Spectroscopy of photoreduction of $\mathrm{CO}_{2}$ by $\mathrm{H}_{2} \mathrm{O}$ at $\mathrm{ZrOCo}{ }^{\mathrm{II}}-\mathrm{IrO}_{\mathrm{x}}$ unit anchored in SBA-15. a Growth of infrared bands of gas phase ${ }^{13} \mathrm{CO}$ upon illumination $(355 \mathrm{~nm})$ of the MMCT absorption in the presence of a gaseous mixture of ${ }^{13} \mathrm{CO}_{2}$ and $\mathrm{H}_{2} \mathrm{O}$. The bottom trace shows that no product growth is observed upon illumination if the Ir oxide nanocluster is synthesized without the photodeposition procedure. $\mathbf{b}$ Trace 1 Detection of $\mathrm{O}_{2}$ product by mass spectroscopy. $\mathrm{No}_{2}$ is formed in the absence of $\mathrm{H}_{2} \mathrm{O}$ (trace 2) or without illumination (trace 3) for otherwise identical samples. c Mass spectra of ${ }^{18} \mathrm{O}_{2}$ and ${ }^{16} \mathrm{O}_{2}$ produced under identical experimental conditions using ${ }^{13} \mathrm{CO}_{2}$ and $\mathrm{H}_{2}^{18} \mathrm{O}$ (trace 4). Trace 5 shows control in the absence of illumination. From Ref. 66, with permission 
in situ X-ray spectroscopy confirmed that the oxidation state of Co rises above III under electrocatalytic oxygen evolution. In situ monitoring of XANES spectra for identifying structural phases present under electrocatalytic conditions has been particularly insightful in the case of Mn oxide catalysts. Rapid-scan FT-IR measurements and ambient pressure XPS results of Ir oxide water oxidation catalysts illustrate the need to probe bond modes and metal electronic structure with these complementary techniques in order to understand the chemical functionalities formed in the catalytic cycle.

When combined with temporally resolved optical monitoring of charge delivery to the catalytic surface site as demonstrated in the case of $\mathrm{Fe}_{2} \mathrm{O}_{3}$ or $\mathrm{SrTiO}_{3}$ photocatalysts, future experiments will explore the detection, by vibrational spectroscopy, of molecular surface intermediates formed by specific charge injection events along the catalytic cycle. Such measurements are the key for pinpointing kinetic bottlenecks and provide the information needed for redesigning surface sites to improve efficiency. Furthermore, by combining temporally resolved infrared spectroscopy of surface intermediates with monitoring of the electronic structure of the metal oxide surface using ultrafast hard and soft X-ray free electron laser sources will greatly enhance our understanding of these multi-electron catalytic processes. The recent demonstration of timeresolved X-ray emission spectroscopy for elucidating the $\mathrm{O}_{2}$-forming step of Nature's water oxidation cycle at the $\mathrm{CaMn}_{4} \mathrm{O}_{4}$ cluster of Photosystem II provides an inspiring example of the use of the emerging ultrafast X-ray free electron laser techniques [100]. Such efforts will play a key role in accelerating progress towards efficient metal oxide catalysts for water oxidation, and the coupling to carbon dioxide reduction.

Acknowledgments This material is based on work supported by the U.S. Department of Energy, Office of Science, Office of Basic Energy Sciences under contract No. DE-AC02-05CH11231. This research used resources of the National Center for Electron Microscopy, Lawrence Berkeley National Laboratory, which is a DOE Office of Science User Facility. The authors thank Dr. Christian Kisielowski for imaging at the TEAM0.5 microscope.

\section{References}

1. Trasatti S (1984) Electrochim Acta 29:1503

2. El-Deab MS, Awad MI, Mohammad AM, Ohsaka T (2007) Electrochem Commun 9:2082

3. Matsumoto Y, Sato E (1986) Mater Chem Phys 14:397

4. Iwakura C, Honji A, Tamura H (1981) Electrochim Acta 26:1319

5. Rasiyah P, Tseung ACC (1983) J Electrochem Soc 130:365

6. Singh RN, Mishra D, Anindita M, Shinha ASK, Singh A (2007) Electrochem Commun 9:1369

7. Schmidt T, Wendt H (1994) Electrochim Acta 39:1763
8. Morita M, Iwakura C, Tamura H (1978) Electrochim Acta 23:331

9. Morita M, Iwakura C, Tamura H (1979) Electrochim Acta 24:357

10. Mraz R, Srb V, Tichy S (1973) Electrochim Acta 18:551

11. Matsumoto Y, Sato E (1979) Electrochim Acta 24:421

12. Fujimura K, Matsui T, Izumiya K, Kumagai N, Akiyama E, Habazaki H, Kawashima K, Asami K, Hashimoto K (1999) Mater Sci Eng, A 267:254

13. Morita M, Iwakura C, Tamaru H (1977) Electrochim Acta 22:325

14. Okuno Y, Yonemitsu O, Chiba Y (1983) Chem Lett 12:815

15. Shafirovich VY, Khannanov NK, Shilov AE (1981) J Inorg Biochem 15:113

16. Harriman A, Pickering IJ, Thomas JM, Christensen PA (1988) J Chem Soc, Faraday Trans I(84):2795

17. Jiao F, Frei H (2009) Angew Chem Int Ed 48:1841

18. Jiao F, Frei H (2010) Energy Environ Sci 3:1018

19. Jiao F, Frei H (2010) Chem Commun 46:2920

20. Pushkar Y, Yano J, Sauer K, Boussac A, Yachandra VK (2008) Proc Natl Acad Sci USA 105:1879

21. Zaharieva I, Najafpour MM, Wiechen M, Haumann M, Kurz P, Dau H (2011) Energy Environ Sci 4:2400

22. Wiechen M, Zaharieva I, Dau H, Kurz P (2012) Chem Sci 3:2330

23. Frey CE, Wiechen M, Kurz P (2014) Dalton Trans 43:4370

24. Gardner GP, Go YB, Robinson DM, Smith PF, Hadermann J, Abakumov A, Greenblatt M, Dismukes GC (2012) Angew Chem Int Ed 51:1616

25. Hara M, Lean JT, Mallouk TE (2001) Chem Mater 13:4668

26. Grzelczak M, Zhang J, Pfrommer J, Hartmann J, Driess M, Antonietti M, Wang X (2013) ACS Catal 3:383

27. Yusuf S, Jiao F (2012) ACS Catal 2:2753

28. Esswein AJ, McMurdo MJ, Ross PN, Bell AT, Tilley TD (2009) J Phys Chem C 113:15068

29. Soo HS, Agiral A, Bachmeier A, Frei H (2012) J Am Chem Soc 134:17104

30. Agiral A, Soo HS, Frei H (2013) Chem Mater 25:2264

31. Yuan G, Agiral A, Pellet N, Kim W, Frei H (2014) Faraday Disc. doi:10.1039/C4FD00150H

32. Zhang M, de Respinis M, Frei H (2014) Nat Chem 6:362

33. Kisielowski C, Helveg S, Yuan G, Frei H (2014) Micron. doi:10. 1016/j.micron.2014.07.009

34. Zecchina A, Spoto G, Coluccia S (1982) J Mol Catal 14:351

35. McAlpin JG, Surendranath Y, Dinca M, Stich TA, Stoian SA, Casey WH, Nocera DG, Britt RD (2010) J Am Chem Soc 132:6882

36. Gerken JB, McAlpin JG, Chen JYC, Rigsby ML, Casey WH, Britt RD, Stahl SS (2011) J Am Chem Soc 133:14431

37. Xu XL, Chen ZH, Li Y, Chen WK, Li JQ (2009) Surf Sci 603:653

38. Kanan MW, Nocera DG (2008) Science 231:1072

39. Surendranath Y, Kanan MW, Nocera DG (2010) J Am Chem Soc 132:16501

40. Kanan MW, Yano J, Surendranath Y, Dinca M, Yachandra VK, Nocera DG (2010) J Am Chem Soc 132:13692

41. McAlpin JG, Stich TA, Ohlin CA, Surendranath Y, Nocera DG, Casey WH, Britt RD (2011) J Am Chem Soc 133:15444

42. Du P, Kokhan O, Chapman KW, Chupas PJ, Tiede DM (2012) J Am Chem Soc 134:11096

43. Mulfort KL, Mukherjee A, Kokhan O, Du P, Tiede DM (2013) Chem Soc Rev 42:2215

44. Chivot J, Mendoza L, Mansour C, Pauporte T, Cassir M (2008) Corros Sci 50:62

45. Yeo BS, Bell AT (2011) J Am Chem Soc 133:5587

46. Subbaraman R, Tripkovic D, Chang KC, Strmenik D, Paulikas AP, Hirunsit P, Chan M, Greeley J, Stamenkovic D, Markovic NM (2012) Nat Mater 11:550 
47. Garcia-Mota M, Bajdich M, Viswanathan V, Vojvodic A, Bell AT, Norskov JK (2012) J Phys Chem C 116:21077

48. Bajdich M, Garcia-Mota M, Vojvodic A, Norskov JK, Bell AT (2013) J Am Chem Soc 135:13521

49. Yin Q, Tan JM, Besson C, Geletti YV, Musaev DG, Kuznetsov AE, Luo Z, Hardcastle KI, Hill CL (2010) Science 328:341

50. Liu F, Concepcion JJ, Jurss JW, Cardolaccia T, Templeton JL, Meyer TJ (2008) Inorg Chem 47:1727

51. Concepcion JJ, Jurss JW, Templeton JL, Meyer TJ (2008) Proc Natl Acad Sci 105:17632

52. Tseng HW, Zong R, Muckerman JT, Thummel RP (2008) Inorg Chem 47:11763

53. Concepcion JJ, Jurss JW, Templeton JL, Meyer TJ (2008) J Am Chem Soc 130:16462

54. Polyansky DE, Muckerman JT, Rochford J, Zong R, Thummel RP, Fujita E (2011) J Am Chem Soc 133:14649

55. Wasylenko DJ, Palmer RD, Berlinguette CP (2013) Chem Commun 49:218

56. Boppana VBR, Jiao F (2011) Chem Commun 47:8973

57. Takashima T, Hashimoto K, Nakamura R (2012) J Am Chem Soc 134:1519

58. Gorlin Y, Lassalle-Kaiser B, Benck JD, Gul S, Webb SM, Yachandra VK, Yano J, Jaramillo TF (2013) J Am Chem Soc 135:8525

59. Gorlin Y, Jaramillo TF (2010) J Am Chem Soc 132:13612

60. Hocking RK, Brimblecombe R, Chang LY, Singh A, Cheah MH, Clover C, Casey WH, Speccia L (2011) Nat Chem 3:461

61. McCrory C, Jung S, Peters JC, Jaramillo TF (2013) J Am Chem Soc $135: 16977$

62. Tilak BV (1981) In: Bockris JOM (eds) Comprehensive Treatise of Electrochemistry, vol. 2. Plenum Press: New York, p 1

63. Nakagawa T, Bjorge NS, Murray RW (2009) J Am Chem Soc 131:15578

64. Spurgeon JM, Velasquez JM, McDowell MT (2014) PhysChemChemPhys 16:3623

65. Swierk JR, Mallouk TE (2013) Chem Soc Rev 42:2357

66. Kim W, Yuan G, McClure BA, Frei H (2014) J Am Chem Soc 136:11034

67. Frame FA, Townsend TK, Chamousis RL, Sabio EM, Dittrich T, Browning ND, Osterloh FE (2011) J Am Chem Soc 133:7264

68. Sivasankar N, Weare WW, Frei H (2011) J Am Chem Soc 133:12976

69. Nagakawa T, Beasley CA, Murray RW (2009) J Phys Chem C 113:12958

70. Kuwabara T, Tomita E, Sakita S, Hasegawa D, Sone K, Yagi M (2008) J Phys Chem C 112:3774

71. Sanchez Casalongue HG, Ng ML, Kaya S, Friebel D, Ogasawara H, Nilsson A (2014) Angew Chem Int Ed 53:7169

72. Rossmeisl J, Qu ZW, Zhu H, Kroes GJ, Norskov JK (2007) J Electroanal Chem 607:83
73. Blakemore JD, Schley ND, Balcells D, Hull JF, Olack GW, Incarvito CD, Eisenstein O, Brudvig GW, Crabtree RH (2010) J Am Chem Soc 132:16017

74. Nakamura R, Nakato Y (2004) J Am Chem Soc 126:1290

75. Cowan AJ, Tang J, Leng W, Durrant JR, Klug DR (2010) J Phys Chem C 114:4208

76. Cowan AJ, Barnett CJ, Pendlebury SR, Barroso M, Sivula K, Graetzel M, Durrant JR, Klug DR (2011) J Am Chem Soc 133:10134

77. Waegele MM, Chen X, Herlihy DM, Cuk T (2014) J Am Chem Soc 136:10632

78. Barroso M, Mesa CA, Pendlebury SR, Cowan AJ, Hisatomi T, Sivula K, Graetzel M, Klug DR, Durrant JR (2012) Proc Natl Acad Sci USA 109:15640

79. Young KMH, Klahr BM, Zandi O, Hamann TW (2013) Catal Sci Technol 3:1660

80. Chadwick Ellis W, McDaniel ND, Bernhard S, Collins TJ (2010) J Am Chem Soc 132:10990

81. Fillol JL, Codola Z, Garcia-Bosch I, Gomez L, Pla JJ, Costas M (2011) Nat Chem 3:807

82. Meekins BH, Kamat PV (2011) J Phys Chem Lett 2:2304

83. Yamakata A, Kawaguchi M, Nishimura N, Minegishi T, Kubota J, Domen K (2014) J Phys Chem C 118:23897

84. Xiang X, Fielden J, Rodriguez-Cordoba W, Huang Z, Zhang N, Luo Z, Musaev DG, Lian T, Hill CL (2013) J Phys Chem C 117:918

85. Youngblood WJ, Lee SHA, Kobayashi Y, Hernandez-Pagan EA, Hoertz PG, Moore TA, Moore AL, Gust D, Mallouk TE (2009) J Am Chem Soc 131:926

86. Lin W, Frei H (2005) J Am Chem Soc 127:1610

87. Lin W, Frei H (2005) J Phys Chem B 109:4929

88. Han H, Frei H (2007) Microporous Mesoporous Mater 103:265

89. Han H, Frei H (2008) J Phys Chem C 112:8391

90. Han H, Frei H (2008) J Phys Chem C 112:16156

91. Okamoto A, Nakamura R, Osawa H, Hashimoto K (2008) Langmuir 24:7011

92. Okamoto A, Nakamura R, Osawa H, Hashimoto K (2008) J Phys Chem C 112:19777

93. Wu X, Weare WW, Frei H (2008) Dalton Trans: 10114

94. Frei H (2009) Chimia 63:721

95. Cuk T, Weare WW, Frei H (2010) J Phys Chem C 114:9167

96. Soo HS, Macnaughtan ML, Weare WW, Yano J, Frei H (2011) J Phys Chem C 115:24893

97. Macnaughtan ML, Soo HS, Frei H (2014) J Phys Chem C 118:7874

98. McClure BA, Frei H (2014) J Phys Chem C 118:11601

99. Andersen LK, Frei H (2006) J Phys Chem B 110:22601

100. Kern J et al (2014) Nat Commun. doi:10.1038/ncomms5371 